\title{
PULP REVASCULARIZATION OF IMMATURE DOG TEETH WITH APICAL PERIODONTITIS
}

\author{
By \\ Blayne Thibodeau, DMD
}

\begin{abstract}
A thesis submitted to the faculty of the University of North Carolina at Chapel Hill in partial fulfillment of the requirements for the degree of Master of Science in the School of Dentistry (Endodontics).
\end{abstract}

Chapel Hill

2006

\author{
Approved by \\ Advisor: Martin Trope \\ Reader: Mitsuo Yamauchi \\ Reader: Fabricio Teixeira
}


(C) 2006

Blayne Thibodeau, DMD

ALL RIGHTS RESERVED 


\begin{abstract}
Blayne Thibodeau, DMD

Pulp revascularization of immature dog teeth with apical periodontitis

(Under the direction of Martin Trope)
\end{abstract}

Purpose: to examine ability of collagen solution (CS) to aid revascularization of necrotic infected root canals in immature dog teeth. Sixty immature teeth (6 dogs) were infected, disinfected and randomized into experimental groups: 1: no further treatment; 2: blood in canal; 3: CS in canal; 4: CS+blood; 5: negative controls (natural development). Uncorrected Chi-squared analysis of radiographic results showed no statistical differences $(p \geq 0.05)$ between experimental groups regarding healing of radiolucencies or radicular thickening; however, group 2 showed significantly more apical closure than group $1(\mathrm{p}=0.01)$. There were no statistical differences between experimental groups for histological results. Groups 1-4 (previously infected) showed positive radiographic outcomes (thickened walls in $35.4 \%$, apical closure in $54.9 \%$, healing radiolucencies in $65.9 \%$ ) and histologic outcomes (thickened walls in $43.9 \%$, apical closure in $54.9 \%$, new luminal tissue in $29.3 \%$ ). A collagen solution did not aid revascularization of disinfected immature dog root canal systems, but revascularization is possible. 


\section{ACKNOWLEDGMENTS}

I would like to thank the following people for helping to bring this project to completion:

The AAE Foundation: This research was supported in part by a Research Grant from the American Association of Endodontists Foundation.

Dr. Martin Trope for mentoring me through this project and guiding me through my three years in the graduate endodontic program at the University of North Carolina.

Dr. Fabricio Teixeira for his hard work, dedication and friendship during this project and throughout my three years in Chapel Hill.

Dr. Mitsuo Yamauchi for his support of this project and his expertise in collagen research.

Dr. Asgeir Sigurdsson for giving me the opportunity to pursue endodontics in this program.

Dr. Paul Teplitsky for his efforts on this project and for nurturing my budding enthusiasm to return to school.

All of the staff of the Department of Laboratory and Animal Medicine at the University of North Carolina for their care of these animals and endless help during the project.

Janice Weaver and the staff of the histology lab for processing the histological specimens.

All of the faculty of the School of Dentistry at the University of North Carolina who challenged me to learn, and passed on their knowledge both in and out of the classroom and clinic.

All of my fellow residents, past and present, for their camaraderie, support and exchange of ideas; in particular, my co-resident, Dr. Judy McIntyre for her enthusiasm, support and friendship now and in the future.

My family and friends who were behind me wholeheartedly while I pursued this goal far from home; in particular, my parents Kathy and Marcel Thibodeau, my friends Dwayne Hooper and Chad Duesener and especially my wife, Dr. Anjani Koneru, without whom I would not be writing this today. 


\section{TABLE OF CONTENTS}

LIST OF TABLES ............................................................................................ vii

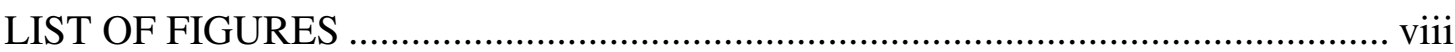

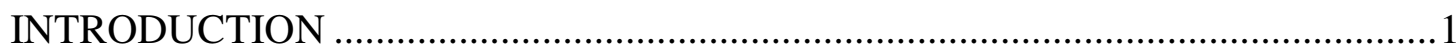

Traumatic dental injuries - incidence, epidemiology .........................................

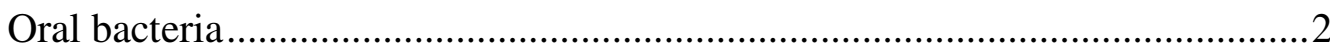

Pulp necrosis and infection ...........................................................................

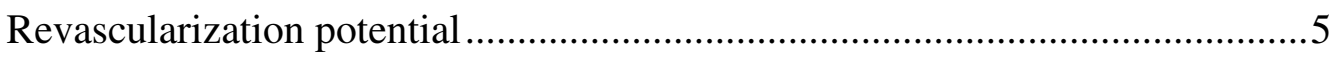

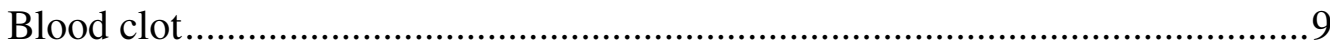

Disinfection of infected canals using antibiotics ............................................11

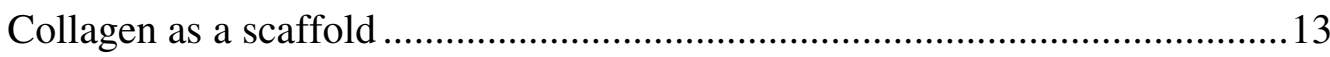

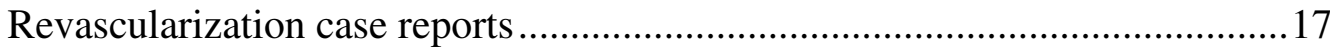

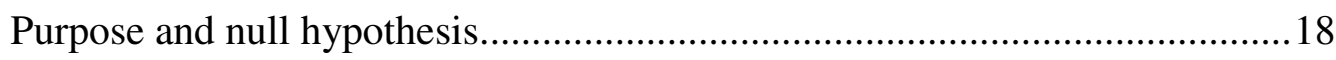

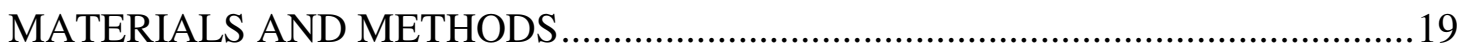

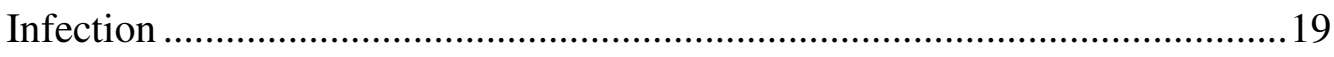

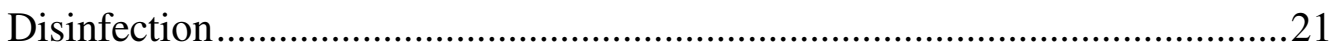

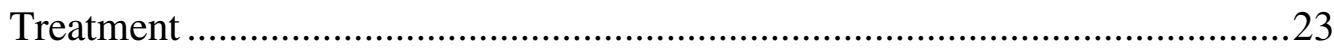

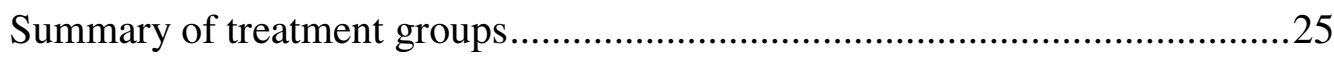

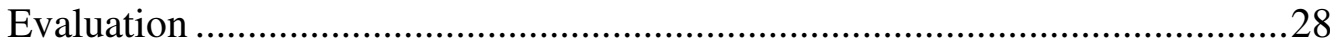

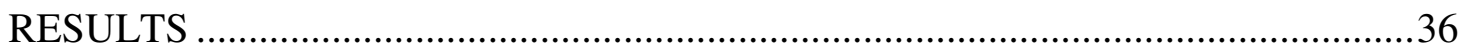


Summary of treatment and control groups at start of project ........................36

Summary of treatment and control groups at completion of project ................37

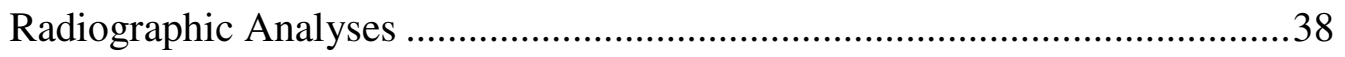

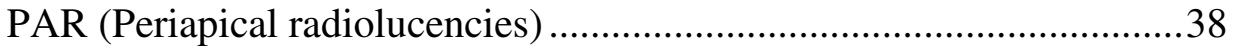

Thickening of radicular walls .......................................................40

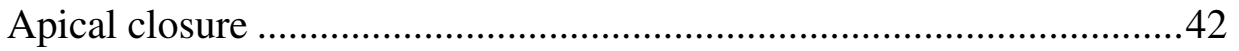

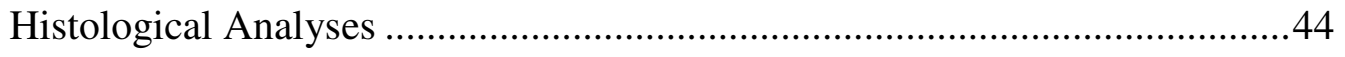

Hard tissue deposition on radicular dentin walls ...............................44

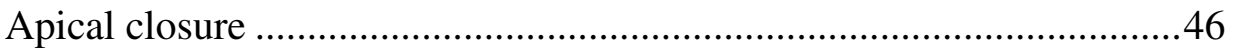

Vital tissue within canal spaces ...................................................48

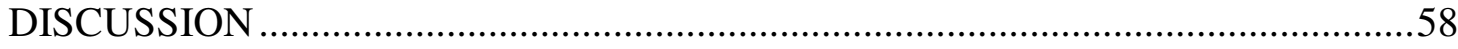

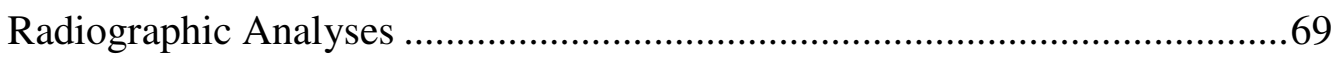

PAR (Periapical radiolucencies) .................................................69

Thickening of radicular walls ...................................................... 70

Apical closure ....................................................................... 71

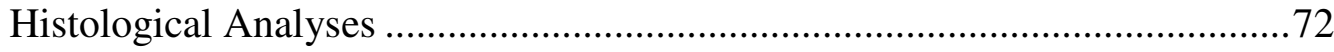

Hard tissue deposition on radicular dentin walls ................................72

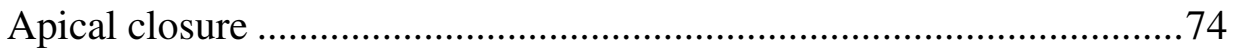

Vital tissue within canal spaces ................................................. 76

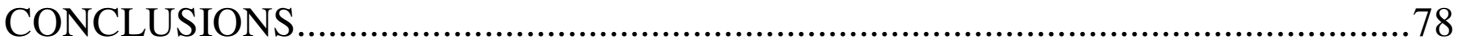

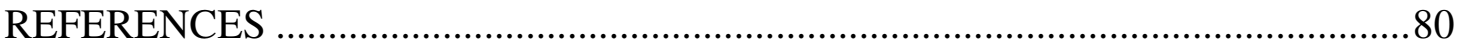




\section{LIST OF TABLES}

Table 1. Allocation of teeth to different groups in each animal

Table 2. Number of roots with presence or absence of a periapical radiolucency assessed radiographically

Table 3. Percentage of roots in experimental groups with and without presence of a periapical radiolucency assessed radiographically.

Table 4. Number of roots with presence or absence of thickened radicular walls assessed radiographically

Table 5. Percentage of roots in experimental groups with presence of thickened radicular walls assessed radiographically

Table 6. Number of roots with presence or absence of apich closure assessed radiographically

Table 7. Percentage of roots in experimental groups with apical closure assessed radiographically

Table 8. Number of roots with presence or absence of hard tissue deposition on radicular dentin walls assessed histologically

Table 9. Percentage of roots in experimental groups with hard tissue deposition on radicular dentin walls assessed histologically

Table 10. Number of roots with presence or absence of apical closure assessed histologically

Table 11. Percentage of roots in experimental groups with apical closure assessed histologically

Table 12. Number of roots with presence or absence of vital tissue within the canal space assessed histologically....

Table 13. Percentage of roots in experimental groups with vital tissue within the canal space assessed histologically.... 


\section{LIST OF FIGURES}

Fig 1. Dentition chart for animal CVHMBY showing experimental group numbers

Fig 2. Dentition chart for animal CVHMCA showing experimental group numbers

Fig 3. Dentition chart for animal CVHMCB showing experimental group numbers

Fig 4. Dentition chart for animal CVHMCC showing experimental group numbers

Fig 5. Dentition chart for animal CVHMCD showing experimental group numbers

Fig 6. Dentition chart for animal CVHMCI showing experimental group numbers

Fig 7. Percentage of roots in experimental groups with and without presence of a periapical radiolucency assessed radiographically

Fig 8. Percentage of roots in experimental groups with and without presence of thickened radicular walls assessed radiographically

Fig 9. Percentage of roots in experimental groups with and without apical closure assessed radiographically

Fig 10. Percentage of roots in experimental groups with and without hard tissue deposition on radicular dentin walls assessed histologically.

Fig 11. Percentage of roots in experimental groups with and without apical closure assessed histologically

Fig 12. Percentage of roots in experimental groups with and without vital tissue within the canal space assessed histologically

Fig 13. Tooth from group 1 (disinfected only) showing thickened root walls, apical development and healing of apical periodontitis. A) Pre-disinfection. B) Post-mortem. C) Histology (original magnification $2 \mathrm{X}$ ) 
Fig 14. Tooth from group 1 (disinfected only) showing persistence of apical periodontitis, thin root walls and lack of development of apices. A) Pre-disinfection. B) Post-mortem. C) Histology (original magnification $2 \mathrm{X}$ )

Fig 15. Tooth from group 2 (blood clot) showing thickened root walls, apical development and healing of apical periodontitis.

A) Pre-disinfection. B) Post-mortem. C) Histology (original magnification $2 \mathrm{X}$ )

Fig 16. Tooth from group 2 (blood clot) showing apical development and ingrowth of new hard tissue. A) Pre-disinfection. B) Post-mortem. C) Histology (original magnification 2X).

Fig 17. Tooth from group 2 (blood clot) showing apical development with normal pulp tissue separated from the root filling by hard tissue.

A) Pre-disinfection. B) Post-mortem. C) Histology (original magnification $2 \mathrm{X}$ )

Fig 18. Tooth from group 3 (collagen only) showing apical hard tissue barrier. A) Pre-disinfection. B) Post-mortem. C) Histology (original magnification $2 \mathrm{X}$ )

Fig 19. Tooth from group 4 (collagen + blood clot) showing apical closure with hard tissue. A) Pre-disinfection. B) Post-mortem.

C) Histology (original magnification $2 \mathrm{X}$ )...

Fig 20. Tooth from group 5 (negative control) showing continued apical and radicular development with normal pulp tissue.

A) Early stage. B) Post-mortem. C) Histology (original magnification $2 \mathrm{X}$ )

Fig 21. Percentages of roots in each experimental group showing positive outcomes measured radiographically

Fig 22. Percentages of roots in each experimental group showing positive outcomes measured histologically 


\section{INTRODUCTION}

\section{Traumatic dental injuries - incidence, epidemiology}

Traumatic dental injuries occur most often in young patients aged approximately 8-10 years $(1,2)$. The most common teeth involved in traumatic dental injuries are the maxillary central incisors (1). Given the young age of most patients who suffer dental trauma, the roots of the involved teeth are most often incompletely formed at that time and exhibit an open/immature apex. The incidence of pulp necrosis as a result of dental trauma varies with the injury suffered and the degree of development of the apex at the time of trauma. Pulp necrosis as a sequel of traumatic dental injuries to immature teeth varies from $0 \%$ for concussions (3), $0 \%$ for subluxations (3), 9\% for lateral and extrusive luxations (3), to $37.5 \%$

for intrusions (3). Once pulp necrosis occurs, infection of the root canal space will eventually ensue. Due to a reduction in the intrapulpal pressure (4), bacteria will find a way in to the pulp space via surface cracks or exposed dentinal tubules $(5,6)$. Bacterial infection of the root canal space inevitably leads to induction of apical periodontitis $(7,8)$.

Traditional treatment of apical periodontitis involves disinfection of the root canal space. This is achieved by various methods, often in combination, including mechanical 
debridement (9-11), chemical disinfection with intracanal irrigants $(10,12)$, and placement of inter-appointment intracanal medicaments, which traditionally include calcium hydroxide $(10,13)$. By these methods, successful outcomes of endodontic therapy, resulting in healing of apical periodontitis, have been shown $(14,15)$.

\section{Oral bacteria}

Kakehashi, Stanley and Fitzgerald (7) showed conclusively that bacteria cause apical periodontitis. Their classic experiment used gnotobiotic (germ free) rats in comparison with control rats living in a natural environment containing bacteria. Following aseptic pulp exposures left open to the oral environment in the gnotobiotic rats, the pulps did not undergo necrosis. Instead, they were free of inflammation and underwent repair with hard tissue bridging the pulp exposure. In contrast, following pulp exposures in the control animals living in an environment containing bacteria, all of the pulps underwent pulp necrosis and infection of the root canal spaces leading to the development of apical periodontitis and abscess formation.

Moller et al (8) also showed that bacteria are required to cause apical periodontitis. Using a monkey model, Moller et al aseptically devitalized the pulps of teeth using an endodontic file and left the pulp tissue in situ in the root canal. Control teeth were immediately closed with a bacteria-tight coronal seal, while experimental teeth were left open to the oral cavity for auto-inoculation by oral bacteria for approximately one week before they were closed with a bacteria-tight coronal seal. After $6-7$ months, culturing of auto-infected teeth showed infection by $8-15$ bacterial strains per tooth, including both facultative and obligate 
anaerobes. Not all teeth infected by oral bacteria showed radiographic evidence of apical periodontitis. However, histological evaluation showed apical periodontitis associated with all teeth that were infected by oral bacteria, while no or only minor inflammation was seen around the roots of teeth that contained aseptic necrotic material. This study showed conclusively that bacteria within the root canal space are responsible for the development of apical periodontitis. Necrotic tissue, on its own, is not sufficient to induce apical periodontitis.

Obligate anaerobes have been shown to be the most common pathogens involved in root canal infections. Sundqvist in 1976 (6) did an exhaustive study of the bacteria found in infected human root canals. He found that bacteria were culturable from the canals of 18/19 teeth with periapical lesions, while no bacteria could be cultured from the canals of teeth without an associated periapical radiolucency. Eighty three of the 88 strains $(>94 \%)$ that were isolated were found to be obligate anaerobes.

\section{Pulp necrosis and infection}

Pulp necrosis of an immature tooth poses a number of potential complications and contributes some unique problems to its treatment. The traditional techniques of chemomechanical instrumentation and disinfection of the root canal system used in mature teeth are limited by the anatomy of the immature tooth. Specifically, it is difficult to mechanically prepare the canal space with conventional endodontic techniques using files and reamers. In addition, the open apex is difficult or impossible to seal with conventional root filling techniques of cold lateral condensation or even with thermoplasticized techniques because of 
the absence of an apical stop. Furthermore, the arrested development of the dentinal walls at the time of necrosis of the pulp leaves a weak tooth with thin dentinal walls that are susceptible to fracture. Root reinforcement techniques for immature, thin-walled teeth have been advocated; however, they can make root canal re-treatment difficult or even impossible if the need arises in the future (16). Finally, recent concerns have arisen regarding the traditional treatment of immature necrotic teeth with apical periodontitis because it involves long term application of calcium hydroxide (up to 18 months (17)) to induce apexification (formation of an apical hard tissue barrier). Andreasen and others recently showed that long term calcium hydroxide treatment may leave the tooth weaker and more susceptible to fracture, emphasizing the need for an improved treatment technique (18).

Calcium hydroxide has been advocated as a medicament to treat vital pulp exposures, just as it is recommended in the traditional treatment of pulpless teeth with open apices. The goal in both scenarios is the formation of a hard tissue barrier by vital tissue. Sciaky and Pisanti $(19,20)$ showed that the effect of the calcium hydroxide in direct pulp capping was not to provide a ready source of calcium ions for a dentinal bridge. They used radioactively labeled calcium ions in two different experiments on dogs to show that the calcium incorporated into the dentinal bridge did not come from the applied calcium hydroxide, but instead came from the blood stream. By this same theory, it can be extrapolated that other materials besides calcium hydroxide may allow the formation of a hard tissue barrier.

Cox and others (21) showed that calcium hydroxide was not the only medicament that could be placed on an exposed vital pulp leading to pulpal healing and formation of a hard tissue barrier. They used a monkey model with pulp exposures capped by different materials traditionally believed to be caustic to the pulp. In their experimental groups, they used a 
surface seal of ZOE (Zinc Oxide Eugenol) over the capping material (placed directly on the vital pulp) to exclude bacterial leakage. In other groups, the restorative material was placed directly on the vital pulp and filled the entire cavity preparation to the cavosurface margin. Their findings showed that the pulp was able to heal below the ZOE surface sealed restorations. Some pulps even exhibited hard tissue formation of a dentinal bridge over the exposed pulp in direct contact with the purported caustic restorative material when protected on the surface from bacterial leakage via ZOE. The authors concluded that it was the absence of bacteria that was necessary for the formation of a hard tissue barrier and/or healing of the pulp.

This information can be applied to the clinical situation of a pulpless tooth with an open apex. In the traditional treatment technique of calcium hydroxide apexification, the calcium hydroxide is placed directly against the vital tissue present at the periradicular area. By an increase in $\mathrm{pH}$, and by exclusion of bacteria, an environment is created whereby hard tissue is laid down to close off the open apex. Drawing on the Cox et al study of 1987 (21), it can be expected that if a canal with an open apex is maintained bacteria free (or rendered bacteria free), a hard tissue barrier may form at the apex, created by the vital tissues present in the periradicular area.

\section{Revascularization potential}

Drawing from the literature $(22,23)$ and studies on traumatic injuries to immature teeth, some promise for revascularization of the root canal system has arisen. The pulp spaces of some replanted immature teeth have been shown to successfully revascularize. In these 
situations, the un-infected necrotic pulp may act as a scaffold for the ingrowth of new tissue. The absence of bacteria is thought to be a key factor in this process. Because bacteria have been conclusively shown to induce apical periodontitis $(6,7)$, the disinfection of the root canal system of necrotic infected immature teeth is purported to be necessary to create an environment conducive to revascularization of the root canal system. If disinfection of a necrotic infected root canal system in an immature tooth can render the tooth to the same starting point as a necrotic un-infected immature tooth (as in the avulsion scenario), then revascularization may be expected to occur.

Kling et al (22) found 18\% revascularization in 154 immature human avulsed teeth that were replanted in their sockets. They found no revascularization if the apical foramen was narrower than $1 \mathrm{~mm}$ in its mesio-distal dimension. Ebeleseder et al (24), in a retrospective study, reported approximately a $30-40 \%$ chance of pulpal revascularization in replanted avulsed immature permanent human teeth. In both of these reports, the successfully revascularized teeth were not previously infected.

Hitchcock et al (25) showed that un-infected teeth in monkeys subjected to vital apicoectomies were revascularized. They aseptically performed apicoectomies on mature vital roots (with no previous endodontic treatment) in monkeys and left the root tips in place in the alveolar bone. Initially, the remaining pulp tissue in the canals underwent necrosis, but remained aseptic. Inflammatory cells consumed the necrotic debris of the pulp. In time, vital tissue including cementum and PDL (periodontal ligament) grew into the root canal spaces of the teeth, replacing the pulp tissue which it used as a scaffold. The source of the new tissue appeared to be the PDL. The new tissue contained cementoblasts, cellular cementum, fibroblasts and dense collagen bundles and caused almost total obliteration of the pulp space. 
The apicoectomy procedure effectively opened the apex of the surgerized teeth, allowing or encouraging migration of the vital cells from the PDL into the canal space. This scenario resembles that of a tooth with an open apex that undergoes pulpal necrosis without infection of the pulp space. The necrotic un-infected pulp should be resorbed by inflammatory cells, and replaced by ingrowing vital tissue (perhaps from the PDL). If a necrotic infected canal space could be rendered bacteria-free, and a scaffold placed in the canal space, inflammatory cells should also resorb this scaffold, which should then be replaced by vital tissue formed by cells migrating in from the periradicular area (perhaps the PDL).

Cvek and others (26) reported on a study of experimental avulsions and replantations of monkey teeth. An important finding was the fact that no revascularization occurred in teeth with mature apices (apical foramen $<0.5 \mathrm{~mm}$ in diameter). Topical application of doxycycline on the root surface was found to increase the rate of complete pulp revascularization and decrease the concentration of bacteria within the canal space. The relationship between the presence of micro-organisms in the pulpal lumen and pulp revascularization was highly significant, where the presence of micro-organisms was related to inflammatory changes in the pulp and total pulp necrosis. Topical treatment with doxycycline before replantation significantly decreased the frequency of micro-organisms in the pulpal lumen and increased the frequency of complete pulp revascularization in immature teeth by approximately $23 \%$. Doxycycline is bacteriostatic in low concentrations. The concentration used $(0.05 \mathrm{mg} / \mathrm{ml})$ did not cause any harm to the periodontal cells, which were then available for revascularization of the pulp space. Forty one percent of the experimental teeth in these monkeys revascularized after topical doxycycline treatment versus $18 \%$ with no topical treatment with doxycycline. 
Another study by Cvek and others in1990 (27) was undertaken to evaluate the effect of systemic antibiotics on pulp revascularization using a monkey model. Mature teeth $(\leq 0.5$ $\mathrm{mm}$ diameter of apical foramen) had no or insignificant amounts of vital tissue present in their pulpal lumen. Complete revascularization occurred in $18 \%$ of immature teeth. Microorganisms were found in the canals of all mature teeth, whereas in teeth with complete pulp revascularization, only one had bacteria in the pulpal lumen. Complete revascularization was highly dependent on the absence of bacteria within the pulp space. In cases of partial revascularization, the new tissue grew until it contacted micro-organisms within the canal. Prophylactic systemic treatment with doxycycline had no effect on the frequency of pulp revascularization.

In 2000, Yanpiset and Trope (23) reported on a dog study involving the topical use of doxycycline on experimentally avulsed immature dog teeth. It was shown that the topical doxycycline doubled the rate of pulpal revascularization in the experimental teeth in comparison with control teeth that were left dry and not treated with topical doxycycline prior to replantation. The topical doxycycline was effective in killing bacteria on the root surface (and in killing any bacteria that traveled down the PDL space between the root and socket), which allowed an environment where tissue cells at the periapical area were able to migrate into the open root apices and revascularize the canal space.

Ritter and others (28) also reported on the topical use of antibiotics to aid pulpal revascularization. In a dog study of experimental avulsions of immature teeth, they showed that pre-replantation treatment with topical minocycline resulted in revascularization of $91 \%$ of the teeth while topical doxycycline resulted in $73 \%$ with revascularization. These results were much higher in comparison with control teeth soaked in saline prior to replantation 
which only had $33 \%$ revascularization. Again, by keeping the wound free of bacteria, periapical tissue cells were able to re-populate the canal spaces.

\section{Blood clot}

Nygaard-Ostby and Hjortdal published a study in 1971 (29) involving complete canal debridement and partial root fillings in humans. Forty seven teeth were used for the study, 35 of which had a vital pulp, while 12 had pulp necrosis. After canal debridement, bacterial cultures were obtained. Files were passed through the apex of experimental canals to induce bleeding into the unfilled portion, while controls were maintained blood-free. Canals were then filled short of the apex. Seven teeth showed complete repair in the unfilled portion, including resorption lacunae on internal dentin walls filled with new cellular cementum and well-vascularized fibrous connective tissue containing hard tissue deposits around embedded dentin fragments. Partial repair occurred in the unfilled portion of 22 teeth, while no repair was found in 16 teeth, five of which had been vital, while 11 initially had pulp necrosis. Although the blood clot was judged by the authors as beneficial in aiding ingrowth of new tissue, no repair occurred in any of the teeth with initially necrotic pulps, with or without a blood clot in the unfilled portion of the canal. They speculated that intracanal microorganisms were responsible for the failure of tissue ingrowth, although they found no differences in repair between those teeth positive and those negative for bacterial growth at the time of root filling, citing the unreliable nature of the culturing techniques of the time.

In 1978, Horsted and Nygaard-Ostby (30) reported on a human study involving total pulpectomies and partial root fillings in vital teeth. They attempted to induce a blood clot 
from the apical tissues into the unfilled portion of the canal prior to filling it short of the working length. They found no differences between those canals where a blood clot was successfully induced and those without the clot in the unfilled portion of the canal. In both cases, cell-containing hard tissue was deposited into resorption lacunae on internal dentin walls. There was new connective tissue present in the unfilled canal space within a few months of the treatment. The inflammatory response resulted in the resorption defects, which were invariably filled in with hard tissue once the inflammatory response subsided.

Davis and others reported on a dog study in 1971 (31) in which vital total pulpectomies were followed by partial root fillings, $3 \mathrm{~mm}$ short of the instrumented length. Canals were instrumented up to size \#80. Viable tissue devoid of inflammation grew into the canals, and was continuous with the PDL. The authors concluded that adequate access via increased apical foramen size is more important for revascularization than formation of a blood clot within the canal.

Myers and Fountain (32) performed a study on monkeys in which canals were infected prior to attempts at revascularization. In one appointment, the canals were instrumented to large sizes, including irrigating with $5.25 \% \mathrm{NaOCl}$ (sodium hypochlorite) and enlarging the foramen. A blood clot or blood substitute was then placed in the canal. No inter-appointment medicament was used. Revascularization did not occur in these cases. The only tissue that grew into the canals was inflammatory tissue. The canals still contained necrotic debris and micro-organisms. The tissue growing into the canals stopped when meeting micro-organisms. 


\section{Disinfection of infected canals using antibiotics}

Research from a Japanese group has led the way in the dental community in the field of topical antibiotics for the disinfection of carious dentin, infected root canals and periapical lesions.

Hoshino et al (33) used ciprofloxacin, metronidazole and minocycline in combination with or without rifampicin in an in vitro study to test their ability to kill bacteriarecovered from infected root dentin. The sources of the bacteria for their experiment included infected root canal walls, carious dentin, and infected dental pulps. They found that no bacteria could be recovered after exposure to either combination of the antibiotics at concentrations of 25 $\mu \mathrm{g} / \mathrm{ml}$ of each drug. When each drug was tested against the bacteria on its own, substantial reductions in the bacterial concentrations were achieved, but no single antibiotic was able to kill all of the bacteria.

Sato and others (34) studied the ability of a mixture of ciprofloxacin, minocycline and metronidazole to eradicate experimental infection of root dentin by E. coli. In this in vitro study, no E. coli were recoverable after 24 hours of exposure to the drug combination via application to the root canal spaces of artificially infected teeth.

Takushige et al (35) reported on the use of LSTR (Lesion Sterilization and Tissue Repair) treatment of primary human molars. This treatment technique is part of NIET (NonInstrumentation Endodontic Treatment). In this study, 87 primary molars with pulp necrosis (54 of which had radiographic evidence of apical periodontitis) were treated without instrumentation of the root canal spaces. Instead, they were treated with application of 3Mix paste (a mixture of metronidazole, minocycline and ciprofloxacin in macrogol and propylene 
glycol, or mixed with root canal sealer) in reservoirs prepared at the canal orifices. The teeth were then restored permanently. All of the teeth were considered successful, showing healing of sinus tracts and abscesses where present, and normal replacement by succedaneous teeth. However, they did not study the outcomes radiographically for those teeth with pre-operative peri-radicular radiolucencies.

The use of a triple antibiotic paste of ciprofloxacin, metronidazole and minocycline has shown promise in its ability to effectively kill common endodontic pathogens in vitro (33) and in vivo (36). By application of a treatment protocol using this triple antibiotic paste in vivo, it is expected that necrotic infected immature teeth can be rendered to the same starting point as avulsed immature teeth whose pulps are necrotic (due to trauma severing the blood supply to the pulp) but un-infected. If this is successful, revascularization of the pulp space may become predictable in disinfected necrotic immature teeth.

Windley et al (36) studied the use of the triple antibiotic combination of metronidazole, minocycline and ciprofloxacin in a dog model. They performed pulp exposures and autoinfected immature permanent premolar teeth with plaque bacteria until radiographic evidence of apical periodontitis was seen. At subsequent treatment appointments, they did not mechanically instrument the root canals. Instead, the canals were first irrigated with $10 \mathrm{ml}$ of $1.25 \%$ sodium hypochlorite. Subsequently, they treated the canals with the antibiotic combination using concentrations of $20 \mathrm{mg}$ of each antibiotic per ml. Strict asepsis and bacterial sampling controls were used to assess bacterial counts. After irrigation with sodium hypochlorite, bacteria were still present in $90 \%$ of the root canals, with only modest reductions in their counts. After two weeks of exposure to the triple antibiotic paste, they showed a significant reduction in canals with remaining bacteria (only $30 \%$ were culture- 
positive). Further, where bacteria were recovered, they were present in such small amounts that they may not be clinically relevant.

\section{Collagen as a scaffold}

While a bacteria-free canal is a pre-requisite for tissue regeneration, this tissue may not grow into an empty space $(37,38)$. A scaffold is necessary to aid the ingrowth of new tissue into the canal space. Application of a collagen solution is hypothesized to act as a scaffold for the ingrowth of new tissue in the disinfected necrotic immature tooth, just as the uninfected necrotic pulp does in the avulsion scenario.

Previous studies (39-43) have also concentrated on use of a scaffold of collagen gel and crystals of components of hydroxyapatite placed into empty canal spaces to aid movement of cells into the empty pulp space. Reasonable success was achieved with this method in experimental procedures in vital teeth that had undergone pulp removal. However, difficulty was encountered when infected necrotic teeth were treated with this gel following calcium hydroxide treatment intended to disinfect the canal space. It is possible that the limited necrosis caused by the calcium hydroxide (44) in the canal damaged the progenitor cells in the periapical area that are instrumental in revascularization of the pulp space. The use of antibiotic paste should overcome the problem of damage to the progenitor cells, as the antibiotics are not harmful to the host's cells (26). The antibiotics can both disinfect the canal space, and leave the progenitor cells alive to migrate into and re-populate the canal space.

Nevins and others published a series of monkey studies and human case reports utilizing a scaffold to aid ingrowth of tissue into empty pulp spaces. In 1976 (39), they demonstrated the 
use of calfskin collagen gel containing calcium and phosphate salts in aiding ingrowth of tissue into empty monkey root canals. They used the maxillary and mandibular incisor teeth of four rhesus monkeys, all of which had open apices. The vital pulps were removed from all of the canals with endodontic instruments. Half of the teeth were left open to the oral cavity for one week before being re-instrumented and irrigated with normal saline prior to being closed with IRM (Intermediate Restorative Material). After another week, the canals were dressed with the collagen gel after being cultured for bacteria. All of these previously exposed canals were positive for bacteria. Canals were then closed with a bacteria-tight coronal seal. The second group of teeth was debrided of their vital pulp, irrigated with normal saline, and dressed with the collagen gel at the first appointment before closure with a bacteria-tight coronal seal. All of the animals were killed after twelve weeks. Although no numerical results are given, the authors report that several of the teeth in both categories (those initially left open to the oral cavity for auto-infection, and those treated in one appointment) were successfully revascularized with various forms of vascularized soft and hard tissue, including cementum, bone and reparative dentin lining the walls of the root canals. Unsuccessful teeth (no numbers were reported) contained inflammatory tissue and exhibited root resorption. They postulated that the failures were due to bacterial infection. In this study, the authors also point out that no antibodies were formed by the monkeys to the components of the collagen gel. Blood tests were performed throughout the experiment and showed negative results to hemagglutination and Ouchterlony antibody tests.

In 1977, Nevins et al (40) reported on a case of an immature human permanent maxillary lateral incisor treated with their collagen gel. Upon accessing the pulp space, a small amount of pus was found, but vital tissue was still present in the apical area of the canal. Most of the 
apical tissue was reportedly removed with hand instruments and normal saline irrigation. The same non-cross-linked collagen-calcium phosphate gel was applied to the canal space and the access was restored with IRM. The patient's symptoms resolved; and follow-up radiographs at 7 weeks and 6 months demonstrated continued apical development and diffuse radiopacities within the root canal space. Although pus was reportedly present upon access of the pulp, this tooth contained vital tissue, and was not necrotic or infected throughout the pulp space.

In 1978, Nevins and others (41) reported on a study involving six young rhesus monkeys testing the calfskin collagen calcium phosphate gel in vital teeth. They did total pulpectomies with saline irrigation on maxillary and mandibular incisors with open apices. The teeth were treated at the same appointment with the collagen gel and a coronal seal with IRM. Two teeth were also treated with a deep pulpotomy procedure and the remaining vital pulp treated with the collagen gel before sealing the access opening. Of the total pulpectomies treated with the gel, 15/21 (71.4\%) were considered successful. They contained cellular and vascular osteoid and cementum in close apposition to the root canal walls. A normal PDL formed around the apex of the teeth, with no ankylosis occurring. The gel-treated pulpotomies showed continued apical closure and narrowing of the canal space and cementum-like or bone-like tissue in the coronal pulp. Six of the 21 gel-treated empty canals $(28.6 \%)$ exhibited resorption and inflammatory tissue in the canals. Antibody tests (Ouchterlony and hemagglutination tests) from blood samples showed no humoral immune response to the collagen-mineral gel. Again, these teeth contained vital pulp and were not necrotic or infected.

Nevins et al published the results of another monkey study in 1980 (42), this time using a cross-linked collagen-calcium phosphate gel. They used 38 incisor teeth of 9 rhesus monkeys 
for this study. Plugs of the collagen-calcium phosphate gel were applied in partially debrided root canals of 16 teeth ( 8 with pulpotomies and 8 with partial pulpectomies). Fourteen other canals ( 7 with pulpotomies and 7 with partial pulpectomies) were treated with gel devoid of the mineral salts. The animals were sacrificed at varying times up to 8 months. New hard tissue formation was seen in 14/16 (87.5\%) of the teeth treated with the collagen-calcium phosphate gel. At 3 months, vascularized connective tissue containing macrophages and giant cells was seen infiltrating and resorbing the gel. In time, cementum and osteodentin formed within and adjacent to the gel, as well as on the surface of the root canal dentin. Progressive gel resorption and continued hard tissue deposition resulted in tissue regeneration within the root canal space. There was little or no inflammatory response seen in the canals at the longer observation periods. Twelve of the fourteen teeth $(85.7 \%)$ treated with the collagen gel without the mineral crystals had some hard tissue formation, continued root development (both apical and lateral dentin deposition) and calcification of residual gel. The cross-linking of this gel reduced its antigenicity further (in comparison with the noncross-linked collagen gel), enhanced its dimensional stability, and provided a hemostatic quality. The cylindrical cross-linked gel plugs were easy to place, and expanded slightly when in position. The pulps in this experiment were all vital, and none of the canal spaces was entirely debrided of vital tissue. There was no infection in any of these canals.

In 1998, Nevins and Crespi (43) reported a series of four human clinical cases involving the use of Zyplast, a cross-linked bovine dermal collagen gel. All of these cases involved trauma to immature maxillary incisor teeth. All of the canals were first debrided and treated with a traditional application of calcium hydroxide paste for six months until clinical symptoms were alleviated and radiographic signs of periapical lesions were reduced in size. 
At that time, the canals were re-instrumented and filled with Zyplast collagen gel and closed with a bacteria-tight coronal seal. The teeth in this report did not have the same success (hard tissue formation in the canals and continued apical and radicular development) as the previously reported sub-human primate studies of Nevins and others, but these teeth were previously necrotic and infected. Further, the limited necrosis of vital tissue caused by the use of the calcium hydroxide paste (44) may have killed the cells in the periradicular area that might have been available and able to migrate in and revascularize the pulp space in these teeth.

\section{Revascularization case reports}

Case reports have arisen in the literature showing successful use of disinfection protocols and subsequent continued development in vivo in the treatment of immature human teeth with necrotic pulps and apical periodontitis. Rule and Winter described a case in 1966 (45) in which an 11 year old girl was treated for necrosis of the pulp in her lower right first premolar tooth. The tooth was deemed to be non-vital, and associated with a draining sinus tract and radiographic evidence of apical periodontitis. The root canal was cleaned to the level of bleeding tissue at the apex and treated with a poly-antibiotic paste. Two weeks later, the canal was filled with a resorbable iodoform paste as a scaffold and sealed coronally with zinc oxide eugenol cement and amalgam. Subsequent radiographs up to three years postoperatively showed continued root formation, closure of the open root apex and reestablishment of a normal PDL space and lamina dura. 
A case reported in 2001 by Iwaya et al (46) described the treatment of a 13 year old girl in a similar manner for necrosis of the pulp of her lower right second premolar tooth with an associated sinus tract. The canal was not mechanically instrumented during treatment, but was repeatedly dressed with a paste of metronidazole and ciprofloxacin, followed by a bacteria-tight coronal seal at the end of this regimen. Electric pulp testing elicited a positive response, indicating the presence of vital pulp or pulp-like tissue in the canal, five months after treatment. Follow up radiographs showed continued development of the root canal walls as well as closure of the root apex.

One final case report appeared in the literature in 2004 (47), in which an 11 year old boy's necrotic, infected mandibular right second premolar tooth (with an associated sinus tract) was disinfected with the triple antibiotic paste system of metronidazole, minocycline and ciprofloxacin. At a subsequent appointment, the operator mechanically stimulated the vital tissue in the apical area of the canal to induce bleeding and clot formation within the root canal space. A bacteria-tight coronal seal was achieved using Mineral Trioxide Aggregate and a bonded resin restoration. Continued root formation and development was documented radiographically over the following 24 months. In addition, there was a return of positive response to vitality testing.

\section{Purpose and null hypothesis}

The purpose of this study was to examine the ability of a collagen scaffold to aid revascularization of the necrotic infected root canal system in immature dog teeth. The null 
hypothesis is that after disinfection of an infected immature dog root canal system, a scaffold will not improve ingrowth of vital tissue into the pulp space.

\section{MATERIALS AND METHODS}

Approval was obtained for this project from the Institutional Animal Care and Use Committee (IACUC) of the University of North Carolina at Chapel Hill. Sixty premolar teeth from six mongrel dogs (Covance Research, Cumberland, Virginia), aged approximately five months were randomly divided into five treatment and control groups. Each animal contributed two teeth per group. Eight teeth per dog were treated, while the remaining two teeth served as negative controls and were left to develop naturally for comparison. Every effort was made to minimize the discomfort of the animals involved in this project. Animals were monitored and cared for by Department of Laboratory and Animal Medicine (DLAM) personnel at the University of North Carolina. All personnel involved in this project successfully completed the required training for animal research.

Two operators performed all of the operative procedures on the animals. The assignment of each operator to a specific procedure for a particular tooth was randomized.

\section{Infection}

Pre-operative radiographs were exposed of all of the premolar teeth in each animal using a paralleling device (Dentsply Rinn, Elgin, Illinois) and a bite registration material (Regisil Dentsply Caulk, Milford, Delaware) to reproduce the exact placement of radiographic film 
and angulation of the X-ray beam. This allowed more consistent reproduction of radiographs without distortion or magnification between images for accurate comparisons directly on the films. Radiographs were exposed using a Dens-O-Mat X-ray machine (Philips Medical Systems, Shelton, Connecticut) using the following exposure factors:7.5 mA, $65 \mathrm{kVp}$, and 0.66 seconds. The exception to this protocol was for post-mortem radiographs, which were exposed using a Sirona X-ray machine (Sirona Dental Systems, Bensheim, Germany) using 7 mA, $60 \mathrm{kVp}$ and 0.25 seconds. Radiographs were exposed using digital PSP (PhotoStimulatable Phosphor) plates (Gendex Dental Systems, Des Plaines, Illinois).

In addition to baseline radiographs at the first appointment, the animals underwent general anesthesia with induction by Pentothal (Abbott Laboratories, North Chicago, Illinois) 13.5 $\mathrm{mg} / \mathrm{kg}$ IV (intravenously) and intubation and maintenance with isoflurane (Halocarbon Laboratories, River Edge, New Jersey). Additionally, the animals were anesthetized locally with $0.5 \mathrm{ml}$ of $0.5 \%$ bupivacaine plain (Abbott Laboratories, North Chicago, Illinois) per quadrant for all treatment procedures. The vital pulps of four randomly chosen premolar teeth per dog (from opposite sides of the maxilla versus the mandible) were exposed with a sterile carbide bur (Brassler USA, Savannah, Georgia) in a high speed handpiece (Midwest, Mondovi, Wisconsin) under non-aseptic conditions. Supragingival plaque obtained from scaling the animals' teeth was inoculated in the exposed pulps of the accessed premolar teeth. The access openings of the teeth were then closed with IRM (Intermediate Restorative Material) (Dentsply Caulk, Milford, Delaware). The animals were given Torbugesic (Butorphanol Tartrate, Fort Dodge Animal Health, Fort Dodge, Iowa) $0.2 \mathrm{mg} / \mathrm{kg}$ post-op after these, and all subsequent, operative procedures for analgesia. 
In accordance with the IACUC, the infection procedures were done in different appointments under the same treatment conditions. At the second appointment (approximately one week after the first infection appointment), the dogs had four more randomly chosen premolar teeth in the two remaining un-infected quadrants infected in the same manner as above. This brought the number of infected premolar teeth to 8 per animal and 48 in total.

The premolar teeth of the dogs were monitored radiographically until such time as there was radiographic evidence of apical periodontitis (approximately $2-3$ weeks). The dogs were sedated using medetomidine (Domitor - Medetomidine HCl, Orion Corporation , Espoo, Finland) IM (intramuscularly) at $0.75 \mathrm{mg} / \mathrm{m}^{2}$ which was reversed with Antisedan (atipemazole $\mathrm{HCl}$, Orion Corporation, Espoo, Finland) sq (subcutaneously) $1 \mathrm{mg} / \mathrm{kg}$ during radiographic procedures while using the original bite registrations.

\section{Disinfection}

Once there was radiographic verification of apical periodontitis, the dogs were placed under general anesthesia for a disinfection protocol of the infected pulp spaces. Once under general anesthesia using Pentothal (Abbott Laboratories, North Chicago, Illinois) $13.5 \mathrm{mg} / \mathrm{kg}$ IV (intravenously) and intubation and maintenance with isoflurane (Halocarbon Laboratories, River Edge, New Jersey), the dogs underwent local anesthesia of the premolar teeth involved using $0.5 \mathrm{ml}$ of $0.5 \%$ bupivacaine plain (Abbott Laboratories, North Chicago, Illinois) per quadrant. The crowns of the teeth to be disinfected were isolated with rubber dam. The area of the retractor and adjacent $2 \mathrm{~cm}$ of rubber dam was disinfected with one $\mathrm{ml}$ of $0.12 \%$ 
chlorhexidine (Alpharma USPD, Baltimore, Maryland). The tooth and surrounding rubber dam and retractor were then coated with tincture of iodine (Humco, Texarcana, Texas) and allowed to dry.

The IRM temporary restorations were removed using a sterile carbide bur (Brassler USA, Savannah, Georgia) in a high speed handpiece (Midwest, Mondovi, Wisconsin) with water spray.

Each experimental tooth (48 in total) was disinfected according to the following protocol:

Each tooth underwent slow irrigation with $10 \mathrm{ml}$ of $1 \% \mathrm{NaOCl}$ (sodium hypochlorite) (Clorox, Oakland, California), and was flushed with $10 \mathrm{ml}$ of sterile saline $(0.9 \%$ sodium chloride, Hospira Inc., Lake Forest, Illinois) and dried with sterile paper points (Dentsply Maillefer, Tulsa, Oklahoma). This was followed by application of a triple antibiotic paste of metronidazole, ciprofloxacin and minocycline (Professional Compounding Centers of America, Houston, Texas) in equal portions of each antibiotic mixed with sterile saline (0.9\% sodium chloride, Hospira Inc., Lake Forest, Illinois) to a paste like consistency using a sterile lentulo spiral (Dentsply Maillefer, Johnson City, Tennessee) in a slow speed handpiece (Midwest, Mondovi, Wisconsin). Twelve control teeth (Group 1) were then closed with a double coronal seal consisting of MTA (Mineral Trioxide Aggregate) (Dentsply Tulsa Dental, Johnson City, Tennessee) and silver amalgam (Sybraloy, Kerr Corporation, Orange, California). The remaining 36 teeth were closed with a sterile sponge (Dentsply Maillefer, Johnson City, Tennessee) and IRM (Dentsply Caulk, Milford, Delaware). The animals were given Torbugesic (Butorphanol Tartrate, Fort Dodge Animal Health, Fort Dodge, Iowa) 0.2 $\mathrm{mg} / \mathrm{kg}$ post-op after these operative procedures for analgesia. 


\section{Treatment}

After one month, the animals again underwent general anesthesia using Pentothal (Abbott Laboratories, North Chicago, Illinois) $13.5 \mathrm{mg} / \mathrm{kg}$ IV (intravenously) and intubation and maintenance with isoflurane (Halocarbon Laboratories, River Edge, New Jersey) and local anesthesia using $0.5 \mathrm{ml}$ of $0.5 \%$ bupivacaine plain (Abbott Laboratories, North Chicago, Illinois) per quadrant. Pre-operative radiographs were exposed of the involved teeth using the previously produced bite registrations and paralleling devices. The randomly chosen teeth to be treated were isolated with rubber dam. The area of the retractor and adjacent $2 \mathrm{~cm}$ of rubber dam was disinfected with one $\mathrm{ml}$ of $0.12 \%$ chlorhexidine (Alpharma USPD, Baltimore, Maryland). The tooth and surrounding rubber dam and retractor were then coated with tincture of iodine (Humco, Texarcana, Texas) and allowed to dry.

The IRM temporary restoration (36 teeth in groups 2, 3 and 4) was removed with a sterile carbide bur (Brassler USASavannah, Georgia) in a high speed handpiece (Midwest, Mondovi, Wisconsin) with water spray.

The teeth were randomly treated in the following manner:

Group 2 - 12 teeth: The canals were flushed with $10 \mathrm{ml}$ of $1 \% \mathrm{NaOCl}$ (Clorox, Oakland, California), and dried with sterile paper points (Dentsply Maillefer, Tulsa, Oklahoma). A sterile size \#30 stainless steel K-file (Dentsply Maillefer, Johnson City, Tennessee) was inserted past the apical area of the canals to induce bleeding. Blood was allowed to fill the canals approximately to the level of the CEJ (cemento-enamel junction) where possible. The access openings were then closed with a double coronal seal consisting of MTA (Mineral 
Trioxide Aggregate) (Dentsply Tulsa Dental, Johnson City, Tennessee) and silver amalgam (Sybraloy, Kerr Corporation, Orange, California).

Group 3 - 12 teeth: The canals were flushed with $10 \mathrm{ml}$ of $1 \% \mathrm{NaOCl}$ (Clorox, Oakland, California), and dried with sterile paper points (Dentsply Maillefer,Tulsa, Oklahoma) . A collagen gel scaffold (rat tail collagen $2.33 \mathrm{mg} / \mathrm{ml}$ in 2 x PBS - Phosphate Buffered Saline BD Biosciences, Bedford, Massachusetts) was injected into the canals with a tuberculin syringe (Becton Dickinson and Company, Franklin Lakes, New Jersey) and pushed apically within the canals via a sterile lentulo spiral (Dentsply Maillefer, Johnson City, Tennessee) in a slow speed handpiece (Midwest, Mondovi, Wisconsin). The access openings were then closed with a double coronal seal consisting of MTA (Mineral Trioxide Aggregate) (Dentsply Tulsa Dental, Johnson City, Tennessee) and silver amalgam (Sybraloy, Kerr Corporation, Orange, California).

Group 4-12 teeth: The canals were flushed with $10 \mathrm{ml}$ of $1 \% \mathrm{NaOCl}$ (Clorox, Oakland, Califmia), and dried with sterile paper points (Dentsply Maillefer, Tulsa, Oklahoma). A collagen gel scaffold (rat tail collagen $2.33 \mathrm{mg} / \mathrm{ml}$ in 2 x PBS - Phosphate Buffered Saline BD Biosciences, Bedford, Massachusetts) was injected into the canals with a tuberculin syringe (Becton Dickinson and Company, Franklin Lakes, New Jersey) and pushed apically within the canals via a sterile lentulo spiral (Dentsply Maillefer, Johnson City, Tennessee) in a slow speed handpiece (Midwest, Mondovi, Wisconsin). A sterile size \#30 stainless steel Kfile (Dentsply Maillefer, Johnson City, Tennessee) was inserted through the collagen gel past the apical area of the canals to induce bleeding. Blood was allowed to fill the canal approximately to the level of the CEJ where possible. The access openings were then closed with a double coronal seal consisting of MTA (Mineral Trioxide Aggregate) (Dentsply Tulsa 
Dental, Johnson City, Tennessee) and silver amalgam (Sybraloy, Kerr Corporation, Orange, California).

Group five consisted of 12 negative control teeth that were left untouched throughout the experiment to develop naturally for comparison. These teeth were neither infected nor disinfected, but were left un-operated. They were imaged in radiographs at the same intervals as the experimental teeth.

Type I collagen was obtained from BD Biosciences (Bedford, Massachusetts). The collagen gel was produced from pepsinized rat tail tendon. This treatment removes the telopeptides (both $\mathrm{C}$ and $\mathrm{N}$ terminal non-helical domains) of type I collagen to aid in its solubility, and to reduce its antigenicity.

The animals were given Torbugesic (Butorphanol Tartrate, Fort Dodge Animal Health, Fort Dodge, Iowa) $0.2 \mathrm{mg} / \mathrm{kg}$ post-op after these operative procedures for analgesia.

\section{Summary of treatment groups}

Group 1 - 12 teeth: Infected $\rightarrow$ disinfected

Group $2-12$ teeth: Infected $\rightarrow$ disinfected $\rightarrow$ blood clot

Group 3 - 12 teeth: Infected $\rightarrow$ disinfected $\rightarrow$ collagen

Group $4-12$ teeth: Infected $\rightarrow$ disinfected $\rightarrow$ collagen + blood clot

Group 5 - 12 teeth: negative control. Untouched teeth left to develop naturally for comparison. 
A group of positive control teeth that were infected and not disinfected or treated further was not included in this project. It has been shown historically in other animal studies $(7,8)$ that a group of teeth treated in this manner would have gone on to have necrotic pulps with infected canal spaces, apical periodontitis and eventual periapical abscesses and even radicular cyst formation. None of the teeth in such a group would have had any positive outcomes with respect to either the radiographic or histological criteria used in this study. There would have been no healing of periapical radiolucencies, no thickening of radicular walls, nor apical closure judged radiographically. There would have been no deposition of hard tissue on the internal radicular dentinal walls, no apical closure, nor ingrowth of vital tissue within the canal spaces seen histologically. For ethical reasons, this group was not included in this project.

The animals were sedated with medetomidine (Domitor - Medetomidine HCl,Orion Corporation, Espoo, Finland) IM (intramuscularly) at $0.75 \mathrm{mg} / \mathrm{m}^{2}$ which was reversed with Antisedan (Atipemazole HCl, Orion Corporation, Espoo, Finland) sq (subcutaneously) 1 $\mathrm{mg} / \mathrm{kg}$ on a monthly basis over the following 3 months. Under sedation, radiographs using the original bite registrations and paralleling devices were exposed of the involved premolar teeth to compare for thickening of dentinal walls, apical closure and healing of the periapical radiolucencies.

After 3 months, the animals were sacrificed under general anesthesia provided by Socumb (pentobarbital, Butler Company, Columbus, Ohio) at $30 \mathrm{mg} / \mathrm{kg}$ IV. The carotid arteries were exposed and canulated. The animals were euthanized with additional pentobarbital (Socumb - pentobarbital, Butler Company, Columbus, Ohio) at a dose of $90 \mathrm{mg} / \mathrm{kg}$ IV. The animals were perfused with $10 \%$ buffered formalin (Fisher Scientific, Fair Lawn, New Jersey). The 
jaws with the involved teeth were resected and placed in formaldehyde (Fisher Scientific, Fair Lawn, New Jersey).

After removal of all soft tissue and excess hard tissue from the specimens, they were next placed in Formical (Decal Chemical Corporation, Congers, New York) for decalcification for six days, including one change of the solution. The specimens were subsequently decalcified in Immunocal (Decal Chemical Corporation, Tallman, New York) for two months, undergoing four changes of the solution over that time. Upon removal from the decalcification solution, the specimens were placed under a running tap water wash for 20 minutes followed by immersion in $70 \%$ ethyl alcohol. The specimens were then dehydrated through ascending gradations of ethanol and processed on a Leica TP 1020 dip n' dunk processor (Leica, Wetzlar, Germany) at 45 minutes per station in the following manner: one cycle of $70 \%$ ethanol, two cycles of $80 \%$ ethanol, two cycles of $95 \%$ ethanol, two cycles of $100 \%$ ethanol, two cycles of xylene and two cycles of Paraplast paraffin (Kendall, Mansfield, Massachusetts) at $58^{\circ} \mathrm{C}$. The tissues were then removed from the storage cassettes and embedded in paraffin, and were sectioned on a Leica Jung RM 2045 microtome (Wetzlar, Germany). Sections were made longitudinally every $5 \mu \mathrm{m}$ through the apical foramen of the roots and placed on probe on plus slides. Tissues were stained with Hematoxylin and Eosin and evaluated under light microscopy at up to $10 \mathrm{X}$ magnification for the presence or absence of healthy, vital tissue and revascularization pattern, if any. 


\section{Evaluation}

Each individual root was taken as a unit of measurement/assessment. Three evaluators examined the histological slides of the roots and graded them for the following three parameters: 1) presence or absence of hard tissue on the internal root dentinal walls, 2) presence or absence of apical closure and 3) presence or absence of vital tissue within the canal space. All three evaluators examined the same slide at the same time under identical lighting and magnification conditions using a multi-headed microscope. Each evaluator independently evaluated the specimen for the three parameters noted above. When the results of evaluation of a parameter were not unanimous among all three evaluators, a consensus was reached after discussing the individual situation.

The same three examiners also evaluated the radiographs independently of one another. The digital radiographs were saved to a computer in jpg format. Each examiner separately viewed the image exposed pre-operatively on the day that the roots were disinfected with $\mathrm{NaOCl}$ and the triple antibiotic paste with an image exposed post-mortem after the animals had been sacrificed (both radiographs were exposed using the custom bite registrations). Each examiner graded each radiograph of each root for the following three parameters: 1) presence or absence of a periapical radiolucency, 2) presence or absence of continued thickening of radicular walls and 3) presence or absence of apical closure. In cases where there was not unanimity among all three evaluators with respect to an individual radiographic parameter, the majority result of the individual evaluations was taken as the final evaluation. 
The data were analyzed with Chi squared tests, with the level of significance set at $\mathrm{p}<$ 0.05 , to determine if there were any significant differences between the experimental groups with respect to both the radiographic and histological criteria. 


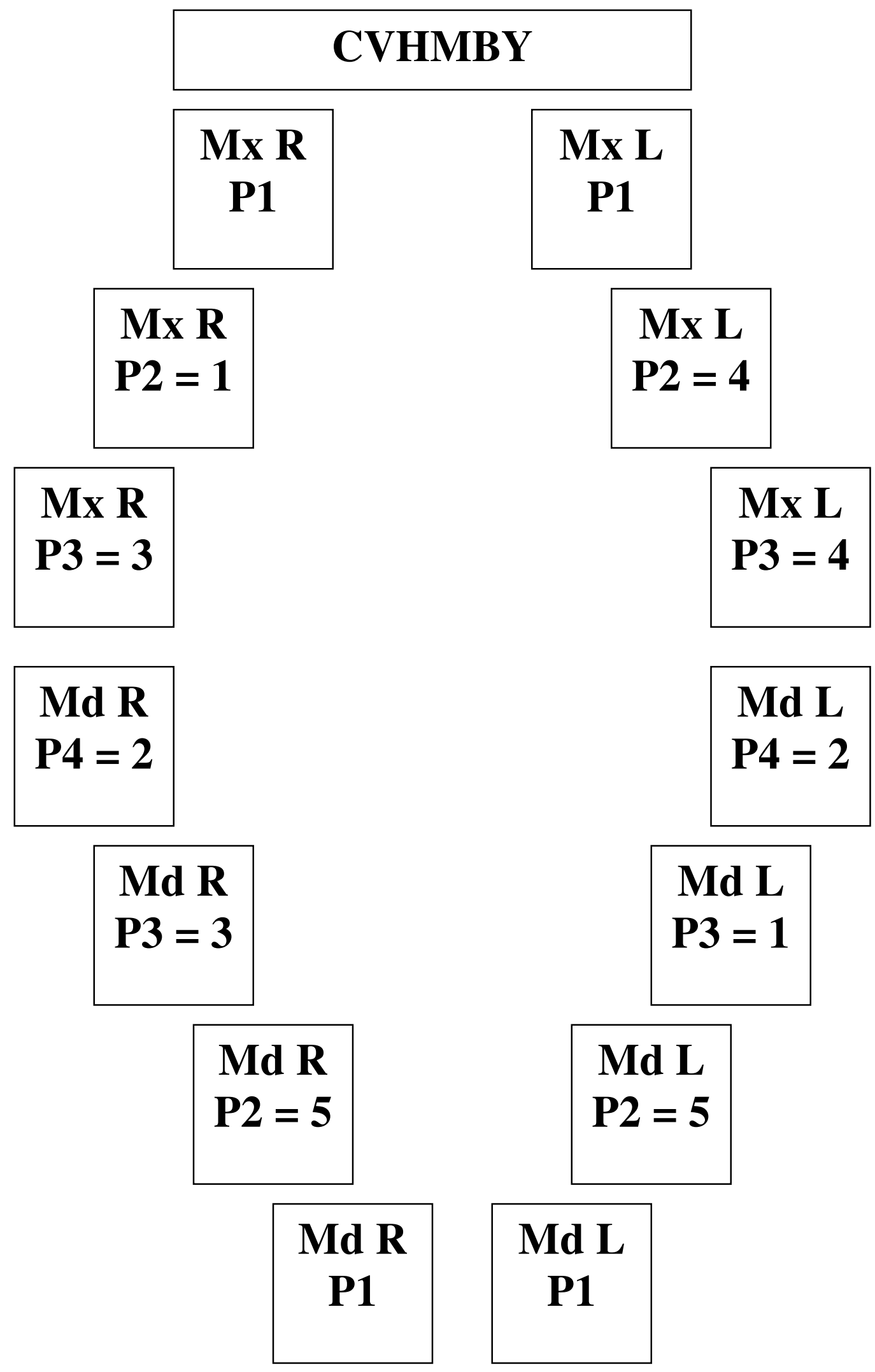

Fig 1. Dentition chart for animal CVHMBY showing experimental group numbers. 


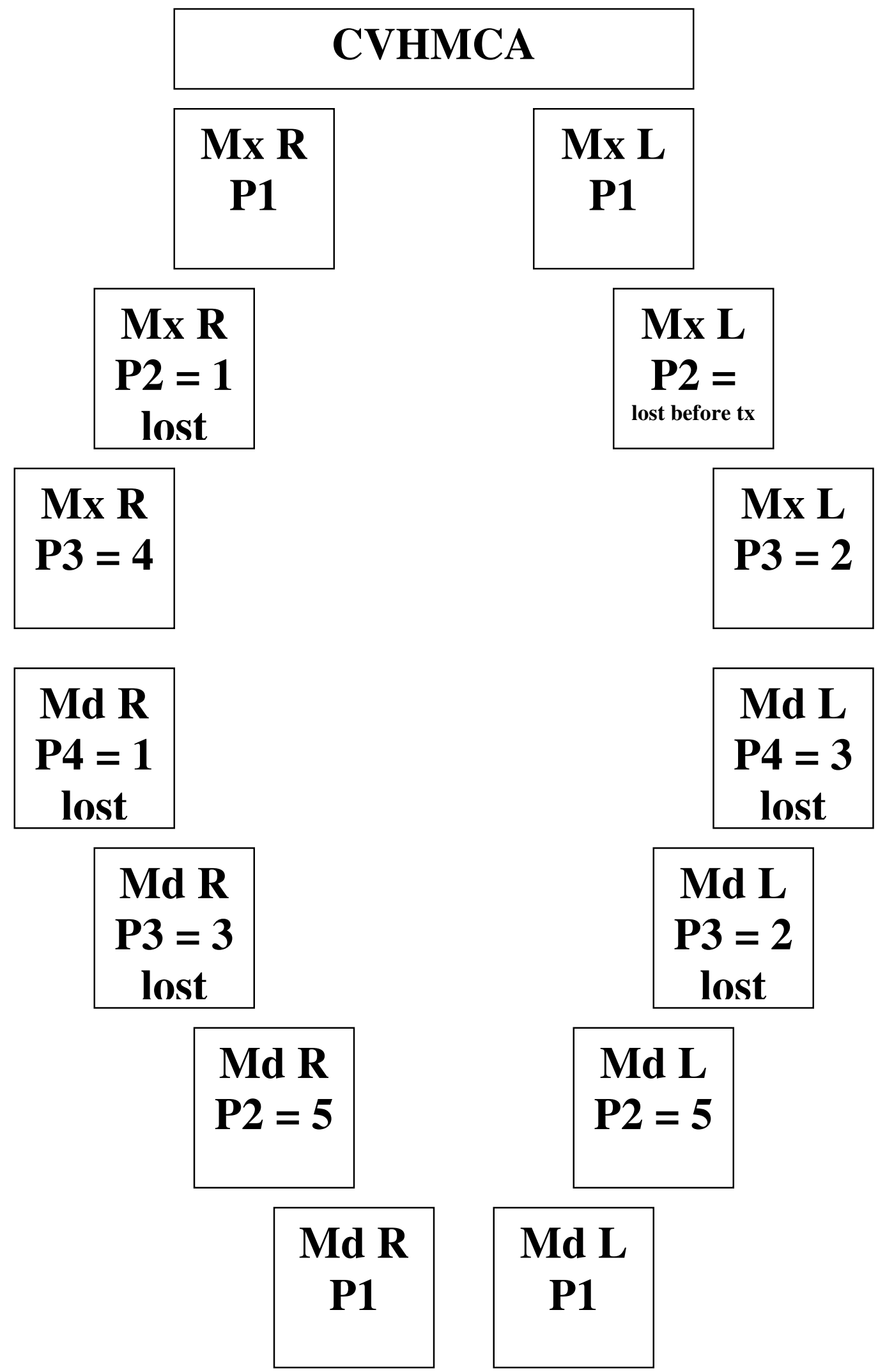

Fig 2. Dentition chart for animal CVHMCA showing experimental group numbers. 


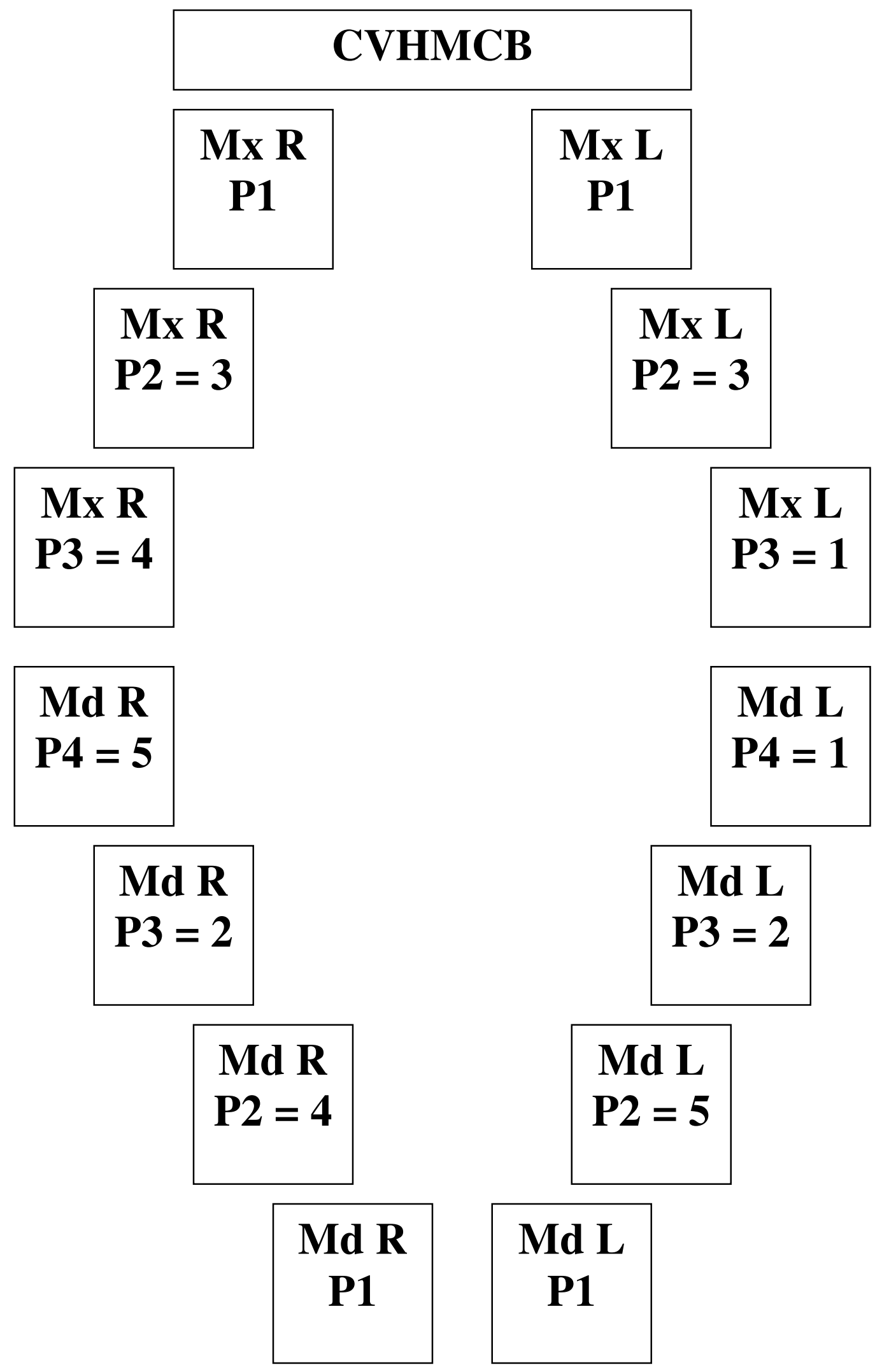

Fig 3. Dentition chart for animal CVHMCB showing experimental group numbers. 


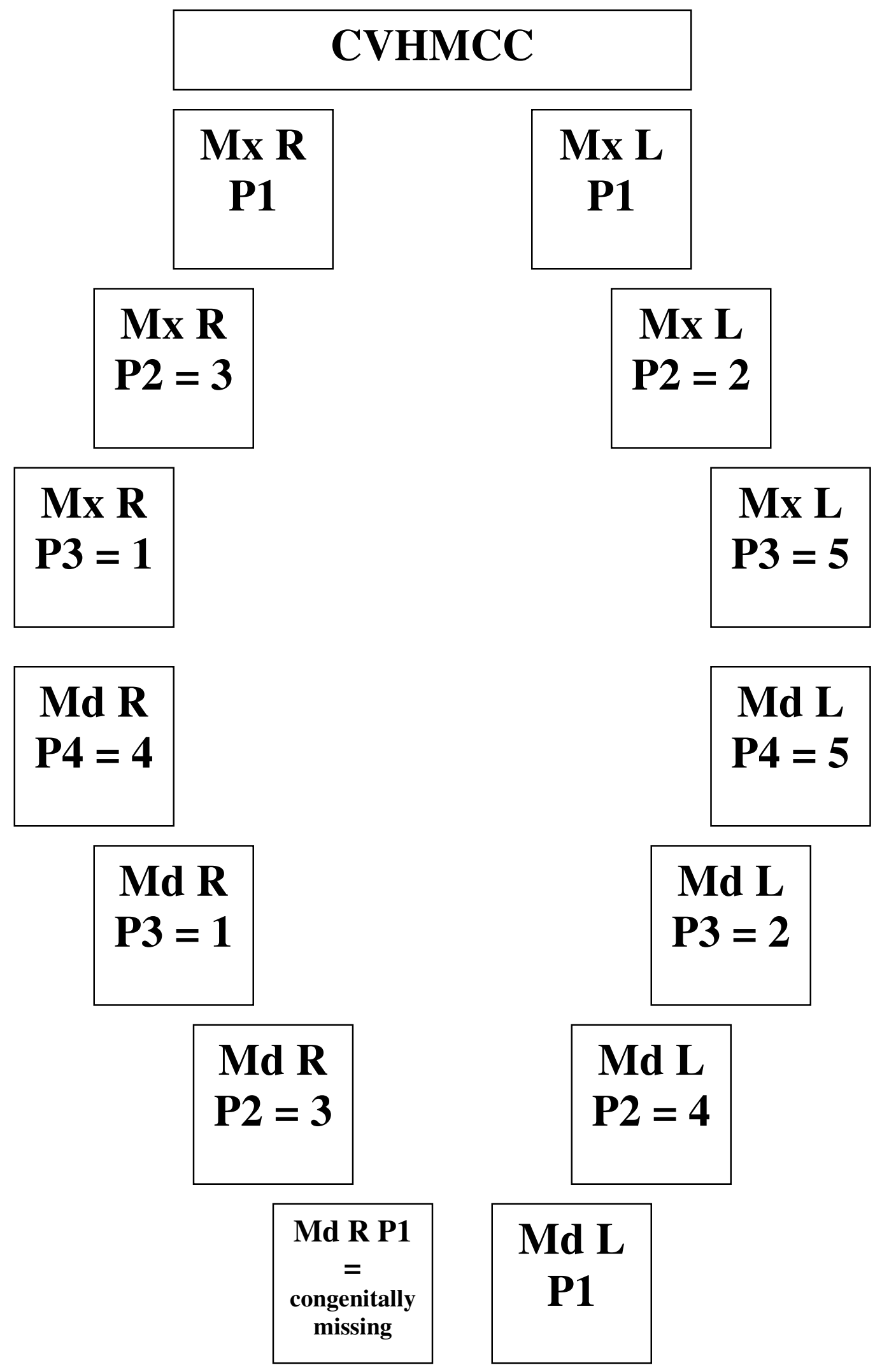

Fig 4. Dentition chart for animal CVHMCC showing experimental group numbers. 


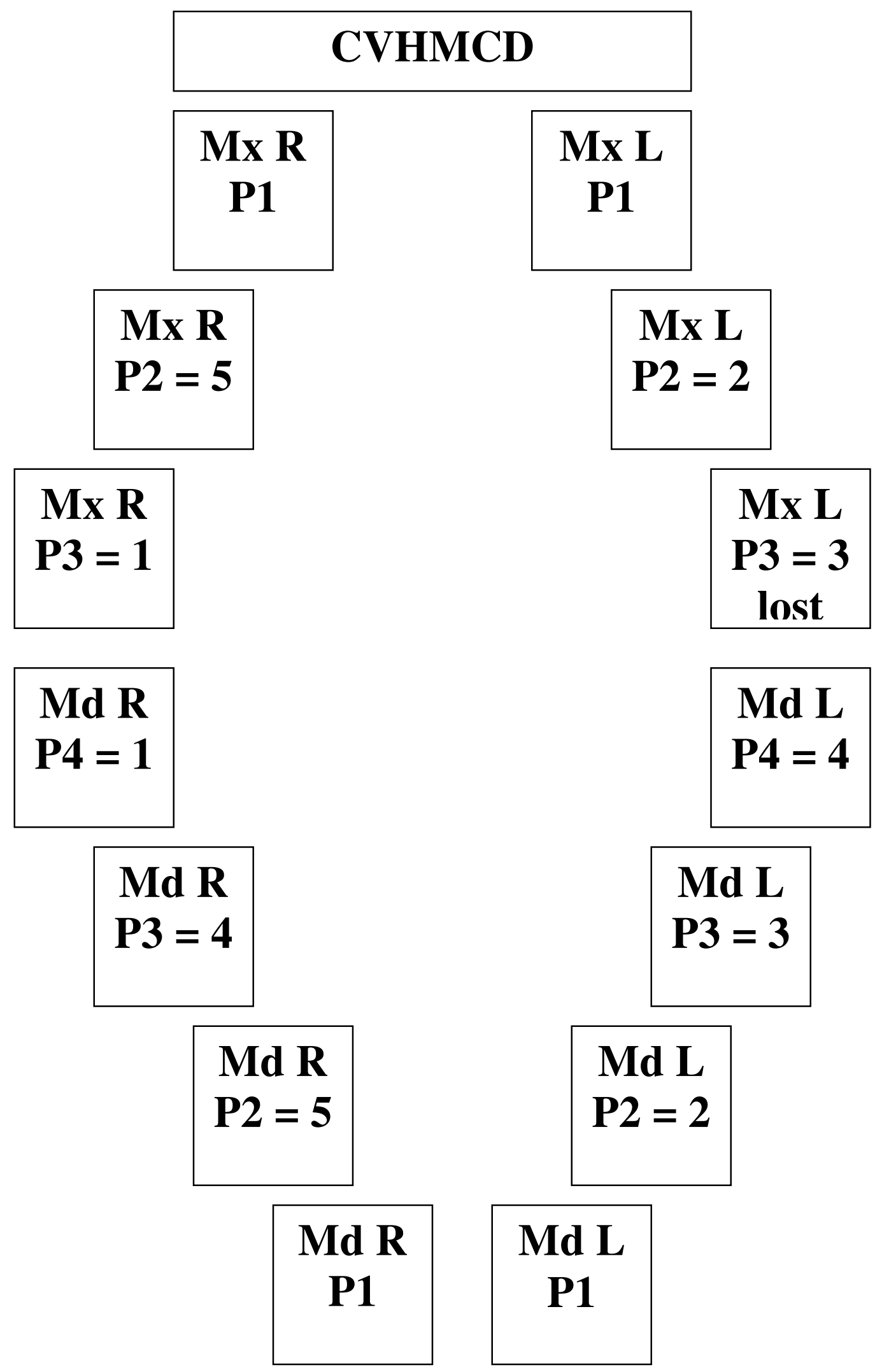

Fig 5. Dentition chart for animal CVHMCD showing experimental group numbers. 


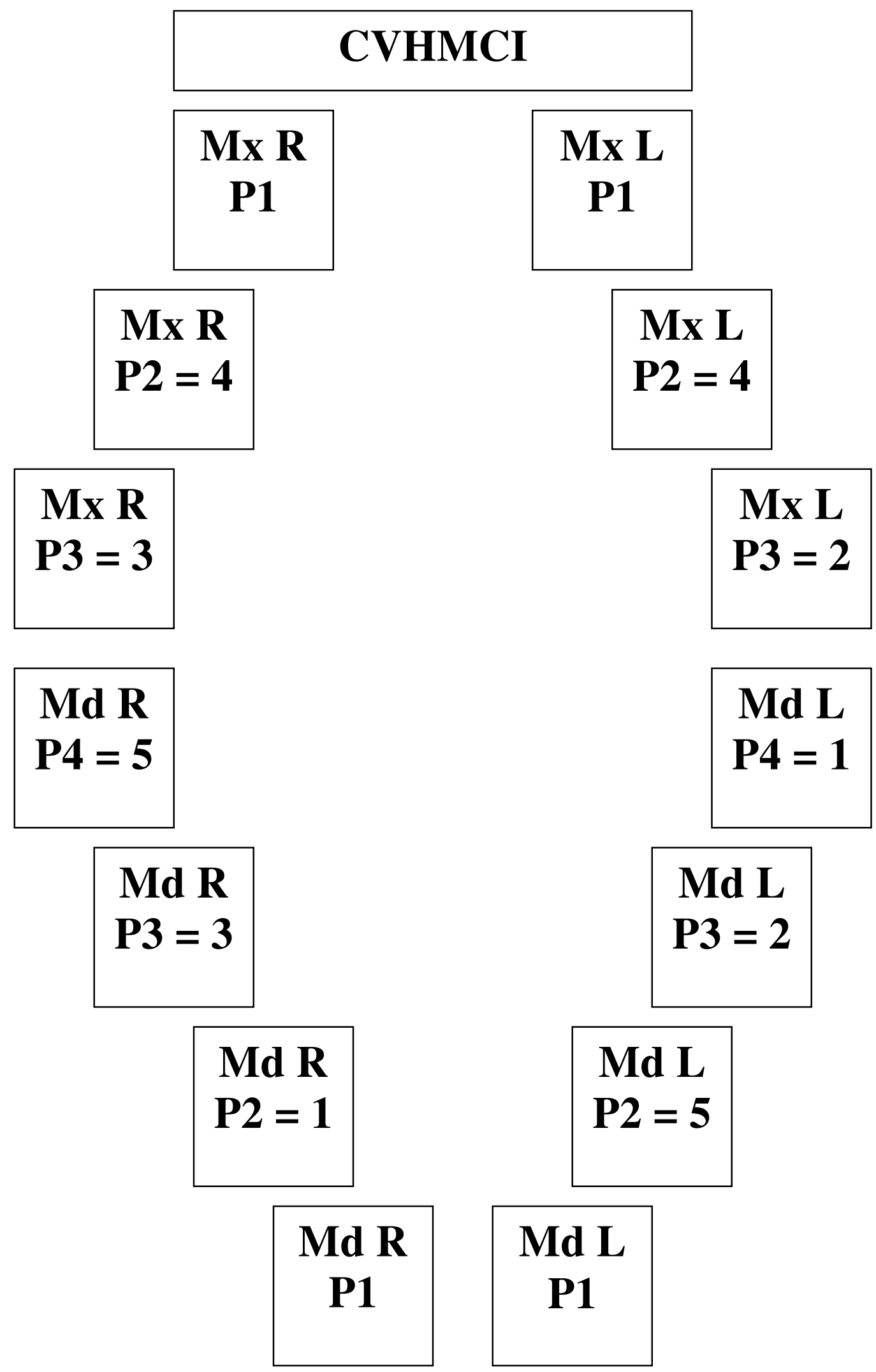

Fig 6. Dentition chart for animal CVHMCI showing experimental group numbers. 
Table 1. Allocation of teeth to different groups in each animal.

\begin{tabular}{|c|c|c|c|c|c|c|}
\hline Animal & & MxR P3 & MxR P2 & MxL P2 & MxL P3 & \\
\hline CVHMBY & & 3 & 1 & 4 & 4 & \\
\hline CVHMCA & & 4 & 1 lost & lost & 2 & \\
\hline CVHMCB & & 4 & 3 & 3 & 1 & \\
\hline CVHMCC & & 1 & 3 & 2 & 5 & \\
\hline CVHMCD & & 1 & 5 & 2 & 3 lost & \\
\hline CVHMCI & & 3 & 4 & 4 & 2 & \\
\hline Animal & MdR P4 & MdR P3 & MdR P2 & MdL P2 & MdL P3 & MdL P4 \\
\hline CVHMBY & 2 & 3 & 5 & 5 & 1 & 2 \\
\hline CVHMCA & 1 lost & 3 lost & 5 & 5 & 2 lost & 3 lost \\
\hline CVHMCB & 5 & 2 & 4 & 5 & 2 & 1 \\
\hline CVHMCC & 4 & 1 & 3 & 4 & 2 & 5 \\
\hline CVHMCD & 1 & 4 & 5 & 2 & 3 & 4 \\
\hline CVHMCI & 5 & 3 & 1 & 5 & 2 & 1 \\
\hline
\end{tabular}

\section{RESULTS}

None of the animals involved in this project exhibited any signs of untoward effects from the experimental interventions. No changes in normal behaviour or eating patterns were noted following intervention/treatment appointments.

\section{Summary of treatment and control groups at start of project}

Group $1-12$ teeth: Infected $\rightarrow$ disinfected

Group $2-12$ teeth: Infected $\rightarrow$ disinfected $\rightarrow$ blood clot

Group $3-12$ teeth: Infected $\rightarrow$ disinfected $\rightarrow$ collagen

Group 4 - 12 teeth: Infected $\rightarrow$ disinfected $\rightarrow$ collagen + blood clot

Group 5 - 12 teeth: negative control. Untouched teeth left to develop naturally for comparison. 


\section{Summary of treatment and control groups at completion of project}

Group 1 - 10 teeth: Infected $\rightarrow$ disinfected

Group 2 - 11 teeth: Infected $\rightarrow$ disinfected $\rightarrow$ blood clot

Group 3 - 9 teeth: Infected $\rightarrow$ disinfected $\rightarrow$ collagen

Group 4 - 11 teeth: Infected $\rightarrow$ disinfected $\rightarrow$ collagen + blood clot

Group 5 - 12 teeth: negative control. Untouched teeth left to develop naturally for comparison.

One animal (CVHMCA) lost 6 experimental teeth during the course of the study. One of these teeth was lost after infection prior to any chance at disinfecting it. The other teeth lost were all extremely mobile after the infection stage; however, they were treated (with respect to their random assignment into groups $1-4$ ) as any other teeth. The other teeth lost included 2 from group 1 (infected $\rightarrow$ disinfected), 2 from group 3 (infected $\rightarrow$ disinfected $\rightarrow$ collagen) and 1 from group 2 (infected $\rightarrow$ disinfected $\rightarrow$ blood clot). These teeth were lost after they had been disinfected and treated according to their random experimental group assignment and closed with a permanent filling. Another animal (CVHMCD) lost one tooth during the study. The tooth was in group 3 (infected $\rightarrow$ disinfected $\rightarrow$ collagen) and was lost after it had been disinfected and treated with the collagen and closed permanently. However, the loss of all of these teeth was not due to the treatment intervention, but was due to the original canal infection. 
The data were subjected to Chi squared evaluations with the level of significance set at $\mathrm{p}<$ 0.05 to determine if there were any statistical differences for each evaluation parameter between the experimental groups.

\section{Radiographic Analyses}

\section{PAR (Periapical radiolucencies)}

Table 2. Number of roots with presence or absence of a periapical radiolucency assessed radiographically.

\begin{tabular}{|c|r|r|r|}
\hline PAR & \multicolumn{1}{|c|}{ Yes } & \multicolumn{1}{c|}{ No } & \multicolumn{1}{c|}{ Total } \\
\hline $\begin{array}{c}\text { Group 1 } \\
\text { disinfected }\end{array}$ & 8 & 12 & 20 \\
\hline $\begin{array}{c}\text { Group 2 } \\
\text { blood clot }\end{array}$ & 7 & 15 & 22 \\
\hline $\begin{array}{c}\text { Group 3 } \\
\text { collagen }\end{array}$ & 6 & 12 & 18 \\
\hline $\begin{array}{c}\text { Group 4 } \\
\text { collagen+ } \\
\text { blood clot }\end{array}$ & 7 & 15 & 22 \\
\hline $\begin{array}{c}\text { Group 5 } \\
\text { negative } \\
\text { controls }\end{array}$ & 0 & 24 & 24 \\
\hline Total & 28 & 78 & 106 \\
\hline
\end{tabular}

Chi squared evaluation of all five groups with respect to presence or absence of a periapical radiolucency showed a significant difference between the groups, with $p=0.02$. Chi squared test for evaluation of all four experimental groups (groups 1 -4), not including the negative control group (group 5), showed there were no significant differences between the four experimental groups with respect to presence or absence of a periapical radiolucency, with $\mathrm{p}=0.94$. 
Table 3. Percentage of roots in experimental groups with and without presence of a periapical radiolucency assessed radiographically.

\begin{tabular}{|c|r|r|}
\hline & \multicolumn{1}{|c|}{$\begin{array}{c}\text { \% with } \\
\text { PAR }\end{array}$} & $\begin{array}{c}\text { \% without } \\
\text { PAR }\end{array}$ \\
\hline $\begin{array}{c}\text { Group 1 } \\
\text { disinfected }\end{array}$ & 40.0 & 60.0 \\
\hline $\begin{array}{c}\text { Group 2 } \\
\text { blood clot }\end{array}$ & 31.8 & 68.2 \\
\hline $\begin{array}{c}\text { Group 3 } \\
\text { collagen }\end{array}$ & 33.3 & 66.7 \\
\hline $\begin{array}{c}\text { Group 4 } \\
\text { collagen+ } \\
\text { blood clot }\end{array}$ & 31.8 & 68.2 \\
\hline overall & 34.1 & 65.9 \\
\hline
\end{tabular}

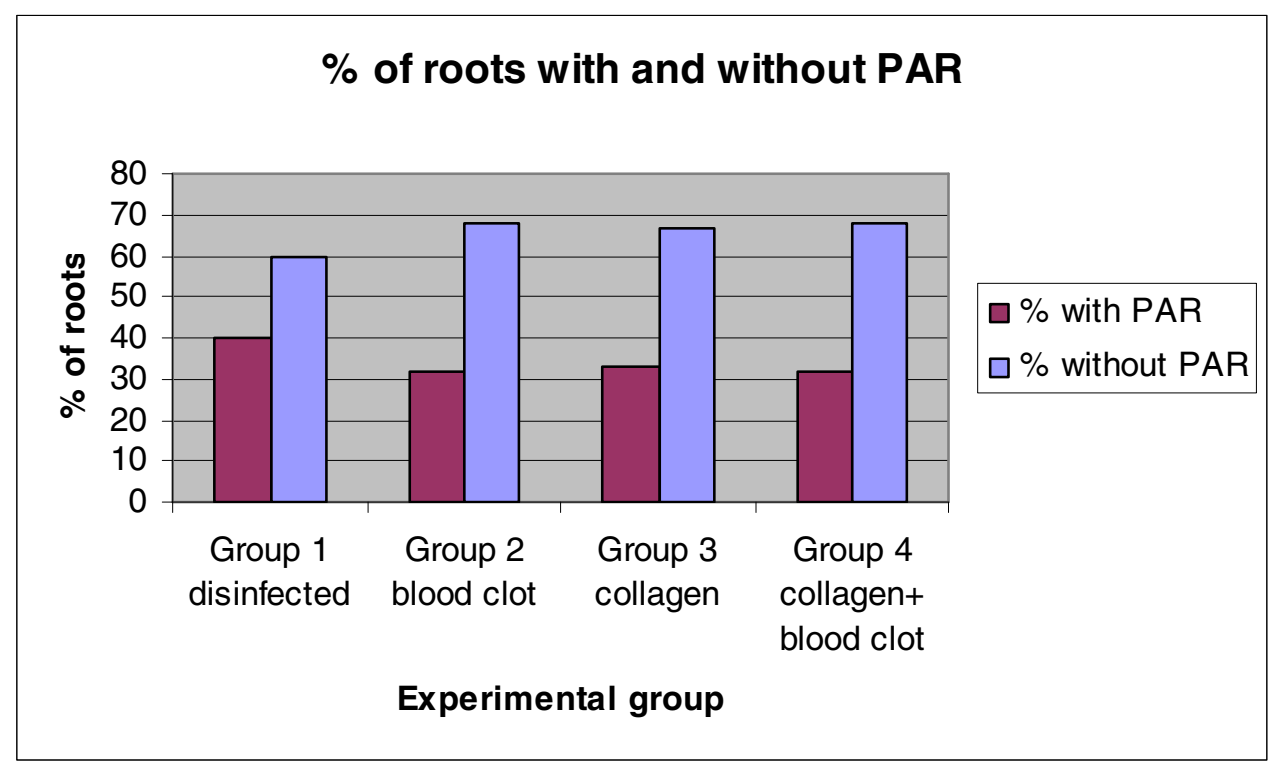

Fig 7. Percentage of roots in experimental groups with and without presence of a periapical radiolucency assessed radiographically.

When comparing the presence or absence of a periapical radiolucency overall with respect to the four experimental groups, it was evident that after disinfection $65.9 \%$ of the roots overall from all groups combined did not show radiographic evidence of a periapical radiolucency. 


\section{Thickening of radicular walls}

Table 4. Number of roots with presence or absence of thickened radicular walls assessed radiographically.

\begin{tabular}{|c|r|r|r|}
\hline Thickened & \multicolumn{1}{|c|}{ Yes } & \multicolumn{1}{|c|}{ No } & \multicolumn{1}{c|}{ Total } \\
\hline $\begin{array}{c}\text { Group 1 } \\
\text { disinfected }\end{array}$ & 5 & 15 & 20 \\
\hline $\begin{array}{c}\text { Group 2 } \\
\text { blood clot }\end{array}$ & 9 & 13 & 22 \\
\hline $\begin{array}{c}\text { Group 3 } \\
\text { collagen }\end{array}$ & 5 & 13 & 18 \\
\hline $\begin{array}{c}\text { Group 4 } \\
\text { collagen+ } \\
\text { blood clot }\end{array}$ & 10 & 12 & 22 \\
\hline $\begin{array}{c}\text { Group 5 } \\
\text { negative } \\
\text { controls }\end{array}$ & 24 & 0 & 24 \\
\hline Total & 53 & 53 & 106 \\
\hline
\end{tabular}

Chi squared evaluation of all five groups with respect to continued thickening of radicular walls assessed radiographically showed a significant difference between the groups, with $\mathrm{p}<$ 0.01. Chi squared test for evaluation of all four experimental groups (groups $1-4$ ), not including the negative control group (group 5), showed there were no significant differences between the four experimental groups with respect to continued thickening of radicular walls judged radiographically, with $\mathrm{p}=0.45$.

Table 5. Percentage of roots in experimental groups with presence of thickened radicular walls assessed radiographically.

\begin{tabular}{|c|c|}
\hline \multicolumn{2}{|c|}{$\begin{array}{c}\text { \% with thickened } \\
\text { walls }\end{array}$} \\
\hline $\begin{array}{c}\text { Group 1 } \\
\text { disinfected }\end{array}$ & 25.0 \\
\hline $\begin{array}{c}\text { Group 2 } \\
\text { blood clot }\end{array}$ & 40.9 \\
\hline $\begin{array}{c}\text { Group 3 } \\
\text { collagen }\end{array}$ & 27.8 \\
\hline $\begin{array}{c}\text { Group 4 } \\
\text { collagen+ } \\
\text { blood clot }\end{array}$ & 45.5 \\
\hline overall & 35.4 \\
\hline
\end{tabular}




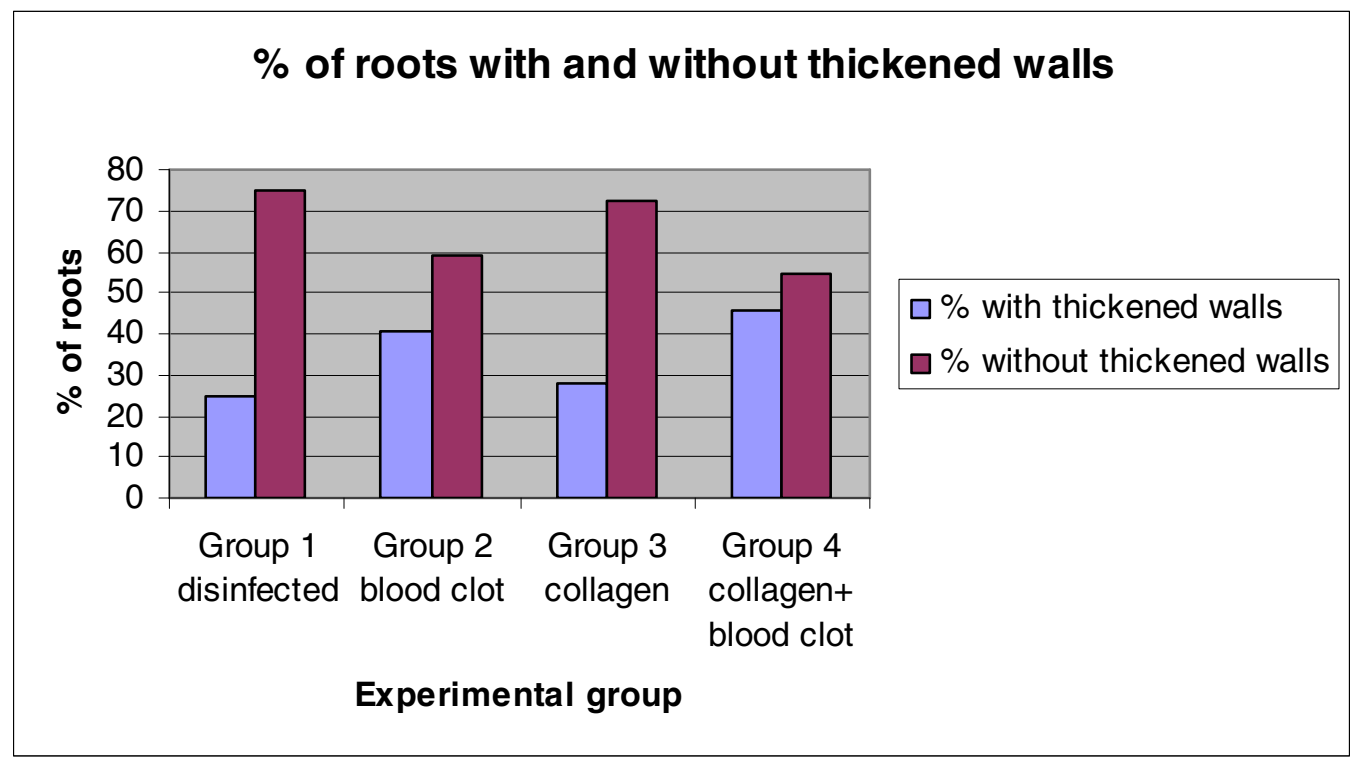

Fig 8. Percentage of roots in experimental groups with and without presence of thickened radicular walls assessed radiographically.

When comparing the continued thickening of radicular dentin walls with respect to the four experimental groups, it was evident that $35.4 \%$ of the roots overall from all groups combined showed radiographic evidence of continued thickening of radicular dentin walls. In groups 2 (infected $\rightarrow$ disinfected $\rightarrow$ blood clot) and 4 (infected $\rightarrow$ disinfected $\rightarrow$ collagen + blood clot), those including use of a blood clot, over $40 \%$ of the roots showed radiographic evidence of continued radicular wall development. Groups 1 (infected $\rightarrow$ disinfected) and 3 (infected $\rightarrow$ disinfected $\rightarrow$ collagen) had approximately $25 \%$ of the roots with continued thickening of radicular dentin walls judged radiographically. 


\section{Apical closure}

Table 6. Number of roots with presence or absence of apical closure assessed radiographically.

\begin{tabular}{|c|r|r|r|}
\hline Closed & \multicolumn{1}{|c|}{ Yes } & \multicolumn{1}{|c|}{ No } & \multicolumn{1}{c|}{ Total } \\
\hline $\begin{array}{c}\text { Group 1 } \\
\text { disinfected }\end{array}$ & 7 & 13 & 20 \\
\hline $\begin{array}{c}\text { Group 2 } \\
\text { blood clot }\end{array}$ & 16 & 6 & 22 \\
\hline $\begin{array}{c}\text { Group 3 } \\
\text { collagen }\end{array}$ & 11 & 7 & 18 \\
\hline $\begin{array}{c}\text { Group 4 } \\
\text { collagen+ } \\
\text { blood clot }\end{array}$ & 11 & 11 & 22 \\
\hline $\begin{array}{c}\text { Group 5 } \\
\text { negative } \\
\text { controls }\end{array}$ & 24 & 0 & 24 \\
\hline Total & 69 & 37 & 106 \\
\hline
\end{tabular}

Chi squared evaluation of all five groups with respect to apical closure showed a significant difference between the groups, with $\mathrm{p}<0.01$. When the individual experimental groups (groups $1-4$ ) were compared with each other using Chi squared tests in $2 \mathrm{X} 2$ tables with one degree of freedom with respect to radiographic evidence of apical closure, a significant difference $(\mathrm{p}=0.01)$ was noted between group 1 (infected $\rightarrow$ disinfected) and group 2 (infected $\rightarrow$ disinfected $\rightarrow$ blood clot), with group 2 (infected $\rightarrow$ disinfected $\rightarrow$ blood clot) showing significantly more apical closure than group 1 (infected $\rightarrow$ disinfected). Chi squared tests for comparison of the other experimental groups, not including the negative control group (group 5), showed there were no other significant differences between the experimental groups with respect to apical closure, with $\mathrm{p}=0.09$. 
Table 7. Percentage of roots in experimental groups with apical closure assessed radiographically.

\begin{tabular}{|c|c|}
\hline \multicolumn{2}{|c|}{ \% with apical closure } \\
\hline $\begin{array}{c}\text { Group 1 } \\
\text { disinfected }\end{array}$ & 35.0 \\
\hline $\begin{array}{c}\text { Group 2 } \\
\text { blood clot }\end{array}$ & 72.7 \\
\hline $\begin{array}{c}\text { Group 3 } \\
\text { collagen }\end{array}$ & 61.1 \\
\hline $\begin{array}{c}\text { Group 4 } \\
\text { collagen+ } \\
\text { blood clot }\end{array}$ & 50.0 \\
\hline overall & 54.9 \\
\hline
\end{tabular}

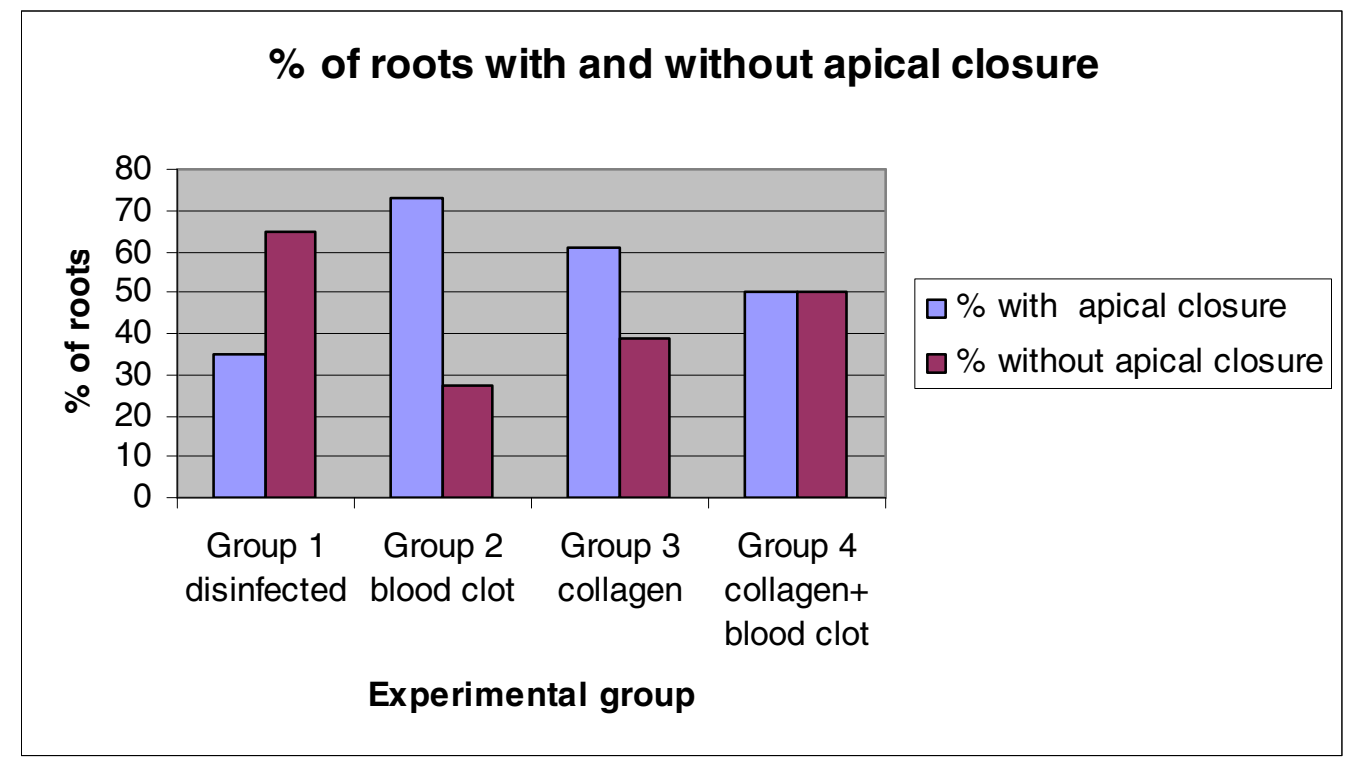

Fig 9. Percentage of roots in experimental groups with and without apical closure assessed radiographically.

When comparing apical closure with respect to the four experimental groups, it was evident that $54.9 \%$ of the roots overall from all groups combined showed radiographic evidence of apical closure. In group 2 (infected $\rightarrow$ disinfected $\rightarrow$ blood clot) more than $70 \%$ of the roots showed radiographic evidence of apical closure. 


\section{Histological Analyses}

\section{Hard tissue deposition on radicular dentin walls}

Table 8. Number of roots with presence or absence of hard tissue deposition on radicular dentin walls assessed histologically.

\begin{tabular}{|c|r|r|r|}
\hline $\begin{array}{c}\text { Hard } \\
\text { tissue }\end{array}$ & \multicolumn{1}{|c|}{ Yes } & \multicolumn{1}{|c|}{ No } & \multicolumn{1}{c|}{ Total } \\
\hline $\begin{array}{c}\text { Group 1 } \\
\text { disinfected }\end{array}$ & 6 & 14 & 20 \\
\hline $\begin{array}{c}\text { Group 2 } \\
\text { blood clot }\end{array}$ & 12 & 10 & 22 \\
\hline $\begin{array}{c}\text { Group 3 } \\
\text { collagen }\end{array}$ & 6 & 12 & 18 \\
\hline $\begin{array}{c}\text { Group 4 } \\
\text { collagen+ } \\
\text { blood clot }\end{array}$ & 12 & 10 & 22 \\
\hline $\begin{array}{c}\text { Group 5 } \\
\text { negative } \\
\text { controls }\end{array}$ & 24 & 0 & 24 \\
\hline Total & 60 & 46 & 106 \\
\hline
\end{tabular}

Chi squared evaluation of all five groups with respect to histological evidence of hard tissue deposition on internal root dentin walls showed a significant difference between the groups, with $\mathrm{p}<0.01$. Chi squared test for evaluation of all four experimental groups (groups $1-4$ ), not including the negative control group (group 5), showed there were no significant differences between the four experimental groups with respect to histological evidence of hard tissue deposition on internal root dentin walls, with $\mathrm{p}=0.22$. 
Table 9. Percentage of roots in experimental groups with hard tissue deposition on radicular dentin walls assessed histologically.

\begin{tabular}{|c|c|}
\hline \multicolumn{2}{|c|}{$\begin{array}{c}\text { \% with hard tissue } \\
\text { on walls }\end{array}$} \\
\hline $\begin{array}{c}\text { Group 1 } \\
\text { disinfected }\end{array}$ & 30.0 \\
\hline $\begin{array}{c}\text { Group 2 } \\
\text { blood clot }\end{array}$ & 54.5 \\
\hline $\begin{array}{c}\text { Group 3 } \\
\text { collagen }\end{array}$ & 33.3 \\
\hline $\begin{array}{c}\text { Group 4 } \\
\text { collagen+ } \\
\text { blood clot }\end{array}$ & 54.5 \\
\hline overall & 43.9 \\
\hline
\end{tabular}

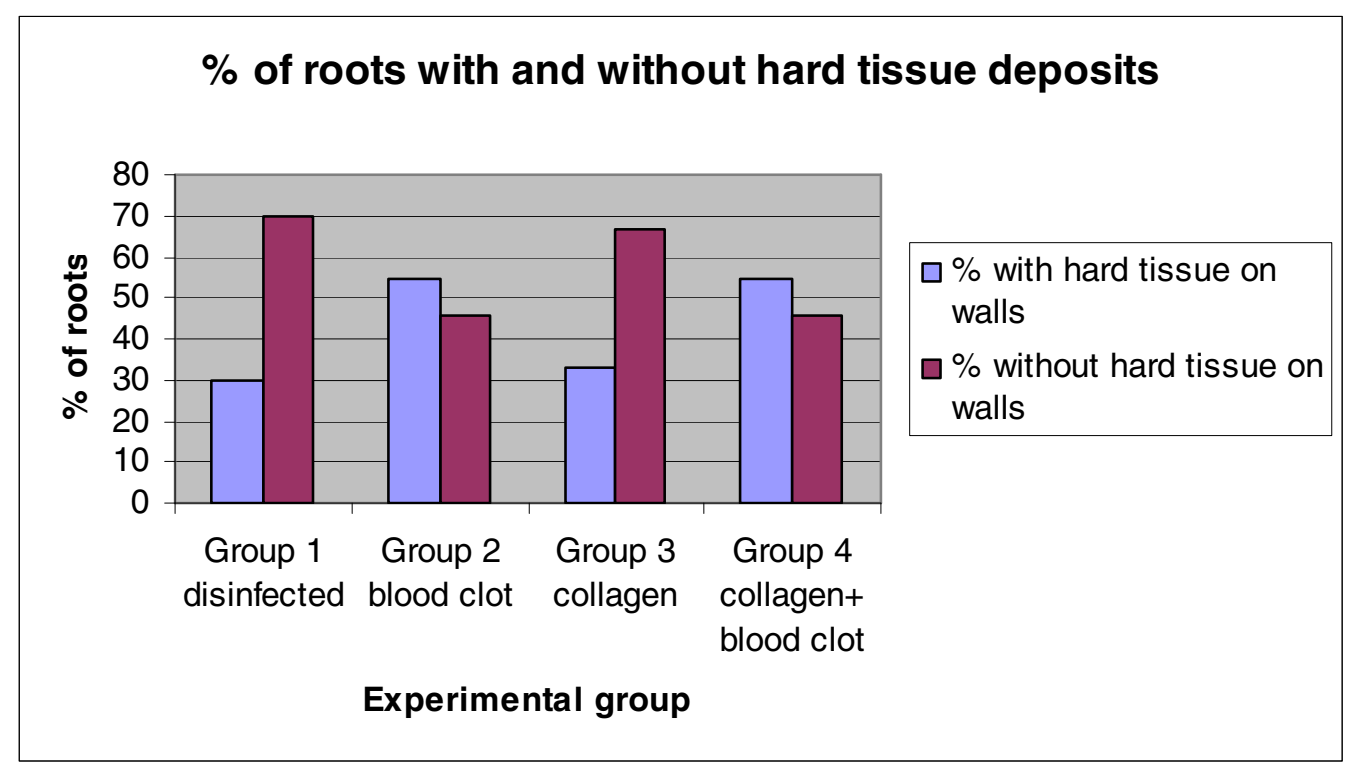

Fig 10. Percentage of roots in experimental groups with and without hard tissue deposition on radicular dentin walls assessed histologically.

When comparing the hard tissue deposition on internal root dentin walls with respect to the four experimental groups, it was evident that $43.9 \%$ of the roots overall from all groups combined showed histological evidence of hard tissue deposition on internal root dentin walls. In groups 2 (infected $\rightarrow$ disinfected $\rightarrow$ blood clot) and 4 (infected $\rightarrow$ disinfected $\rightarrow$ collagen + blood clot), those including the use of a blood clot, more than $54 \%$ of the roots showed histological evidence of hard tissue deposition on internal root dentin walls. Groups 
1 (infected $\rightarrow$ disinfected) and 3 (infected $\rightarrow$ disinfected $\rightarrow$ collagen) showed approximately $30 \%$ of the roots with histological evidence of hard tissue deposited on the internal radicular dentin walls.

\section{Apical closure}

Table 10. Number of roots with presence or absence of apical closure assessed histologically.

\begin{tabular}{|c|r|r|r|}
\hline $\begin{array}{c}\text { Apical } \\
\text { closure }\end{array}$ & \multicolumn{1}{|c|}{ Yes } & \multicolumn{1}{|c|}{ No } & \multicolumn{1}{c|}{ Total } \\
\hline $\begin{array}{c}\text { Group 1 } \\
\text { disinfected }\end{array}$ & 10 & 10 & 20 \\
\hline $\begin{array}{c}\text { Group 2 } \\
\text { blood clot }\end{array}$ & 13 & 9 & 22 \\
\hline $\begin{array}{c}\text { Group 3 } \\
\text { collagen }\end{array}$ & 9 & 9 & 18 \\
\hline $\begin{array}{c}\text { Group 4 } \\
\text { collagen+ } \\
\text { blood clot }\end{array}$ & 13 & 9 & 22 \\
\hline $\begin{array}{c}\text { Group 5 } \\
\text { negative } \\
\text { controls }\end{array}$ & 24 & 0 & 24 \\
\hline Total & 69 & 37 & 106 \\
\hline
\end{tabular}

Chi squared evaluation of all five groups with respect to histological evidence of apical closure showed a significant difference between the groups, with $\mathrm{p}<0.01$. Chi squared test for evaluation of all four experimental groups (groups $1-4$ ), not including the negative control group (group 5), showed there were no significant differences between the four experimental groups with respect to histological evidence of apical closure, with $p=0.88$. 
Table 11. Percentage of roots in experimental groups with apical closure assessed histologically.

\begin{tabular}{|c|c|}
\hline \multicolumn{2}{|c|}{$\%$ with apical closure } \\
\hline $\begin{array}{c}\text { Group 1 } \\
\text { disinfected }\end{array}$ & 50.0 \\
\hline $\begin{array}{c}\text { Group 2 } \\
\text { blood clot }\end{array}$ & 59.1 \\
\hline $\begin{array}{c}\text { Group 3 } \\
\text { collagen }\end{array}$ & 50.0 \\
\hline $\begin{array}{c}\text { Group 4 } \\
\text { collagen+ } \\
\text { blood clot }\end{array}$ & 59.1 \\
\hline overall & 54.9 \\
\hline
\end{tabular}

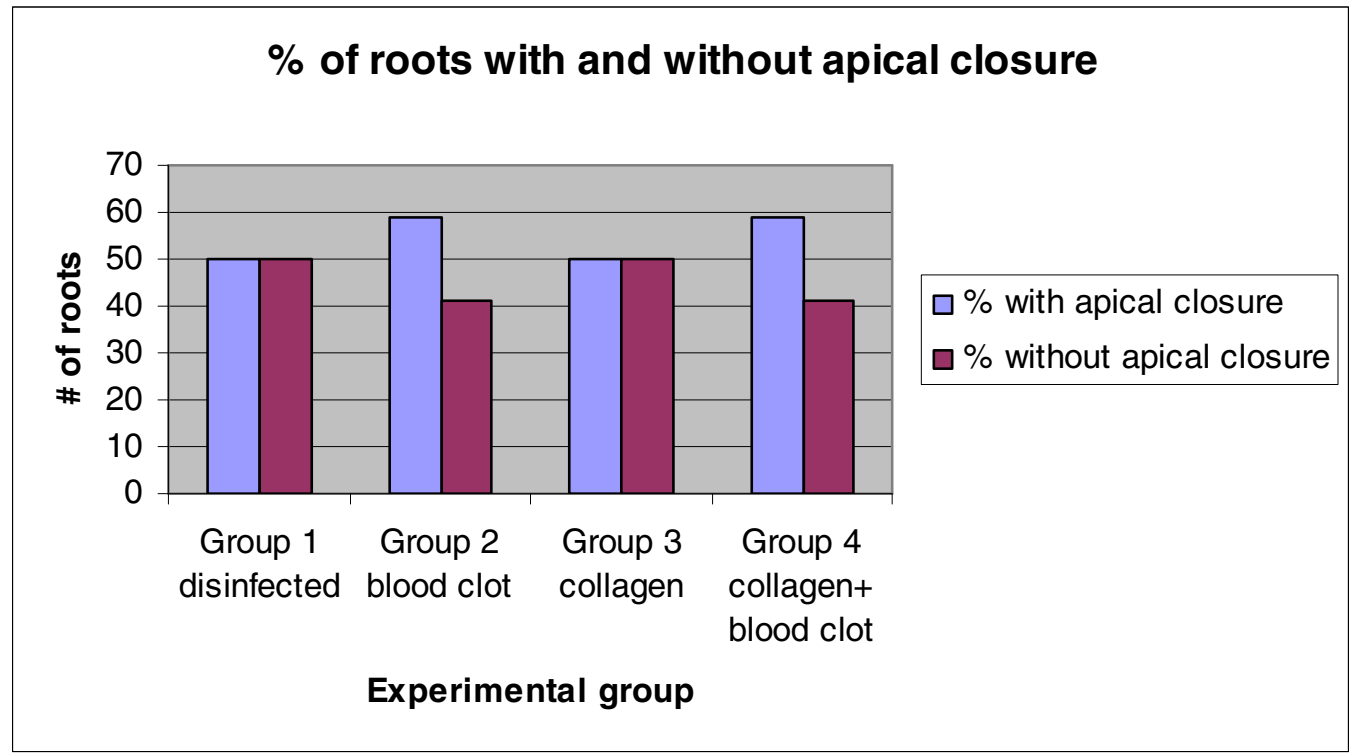

Fig 11. Percentage of roots in experimental groups with and without apical closure assessed histologically.

When comparing the histological evidence of apical closure with respect to the four experimental groups, it was evident that $54.9 \%$ of the roots overall from all groups combined showed histological evidence of apical closure. In groups 2 (infected $\rightarrow$ disinfected $\rightarrow$ blood clot) and 4 (infected $\rightarrow$ disinfected $\rightarrow$ collagen + blood clot $),$ those including the use of a blood clot, more than $59 \%$ of the roots showed histological evidence of apical closure. Half of the roots $(50 \%)$ in groups 1 (infected $\rightarrow$ disinfected) and 3 (infected $\rightarrow$ disinfected $\rightarrow$ collagen) showed histological evidence of apical closure. 


\section{Vital tissue within canal spaces}

Table 12. Number of roots with presence or absence of vital tissue within the canal space assessed histologically.

\begin{tabular}{|c|r|r|r|}
\hline Tissue & \multicolumn{1}{|c|}{ Yes } & \multicolumn{1}{|c|}{ No } & \multicolumn{1}{c|}{ Total } \\
\hline $\begin{array}{c}\text { Group 1 } \\
\text { disinfected }\end{array}$ & 4 & 16 & 20 \\
\hline $\begin{array}{c}\text { Group 2 } \\
\text { blood clot }\end{array}$ & 8 & 14 & 22 \\
\hline $\begin{array}{c}\text { Group 3 } \\
\text { collagen }\end{array}$ & 4 & 14 & 18 \\
\hline $\begin{array}{c}\text { Group 4 } \\
\text { collagen+ } \\
\text { blood clot }\end{array}$ & 8 & 14 & 22 \\
\hline $\begin{array}{c}\text { Group 5 } \\
\text { negative } \\
\text { controls }\end{array}$ & 24 & 0 & 24 \\
\hline Total & 48 & 58 & 106 \\
\hline
\end{tabular}

Chi squared evaluation of all five groups with respect to histological evidence of vital tissue within the canal space showed a significant difference between the groups, with $\mathrm{p}<$ 0.01. Chi squared test for evaluation of all four experimental groups (groups $1-4$ ), not including the negative control group (group 5), showed there were no significant differences between the four experimental groups with respect to histological evidence of vital tissue within the canal space, with $\mathrm{p}=0.51$.

Table 13. Percentage of roots in experimental groups with vital tissue within the canal space assessed histologically.

\begin{tabular}{|c|c|}
\hline \multicolumn{2}{|c|}{$\begin{array}{c}\text { \% with tissue in } \\
\text { canal }\end{array}$} \\
\hline $\begin{array}{c}\text { Group 1 } \\
\text { disinfected }\end{array}$ & 20.0 \\
\hline $\begin{array}{c}\text { Group 2 } \\
\text { blood clot }\end{array}$ & 36.4 \\
\hline $\begin{array}{c}\text { Group 3 } \\
\text { collagen }\end{array}$ & 22.2 \\
\hline $\begin{array}{c}\text { Group 4 } \\
\text { collagen+ } \\
\text { blood clot }\end{array}$ & 36.4 \\
\hline overall & 29.3 \\
\hline
\end{tabular}




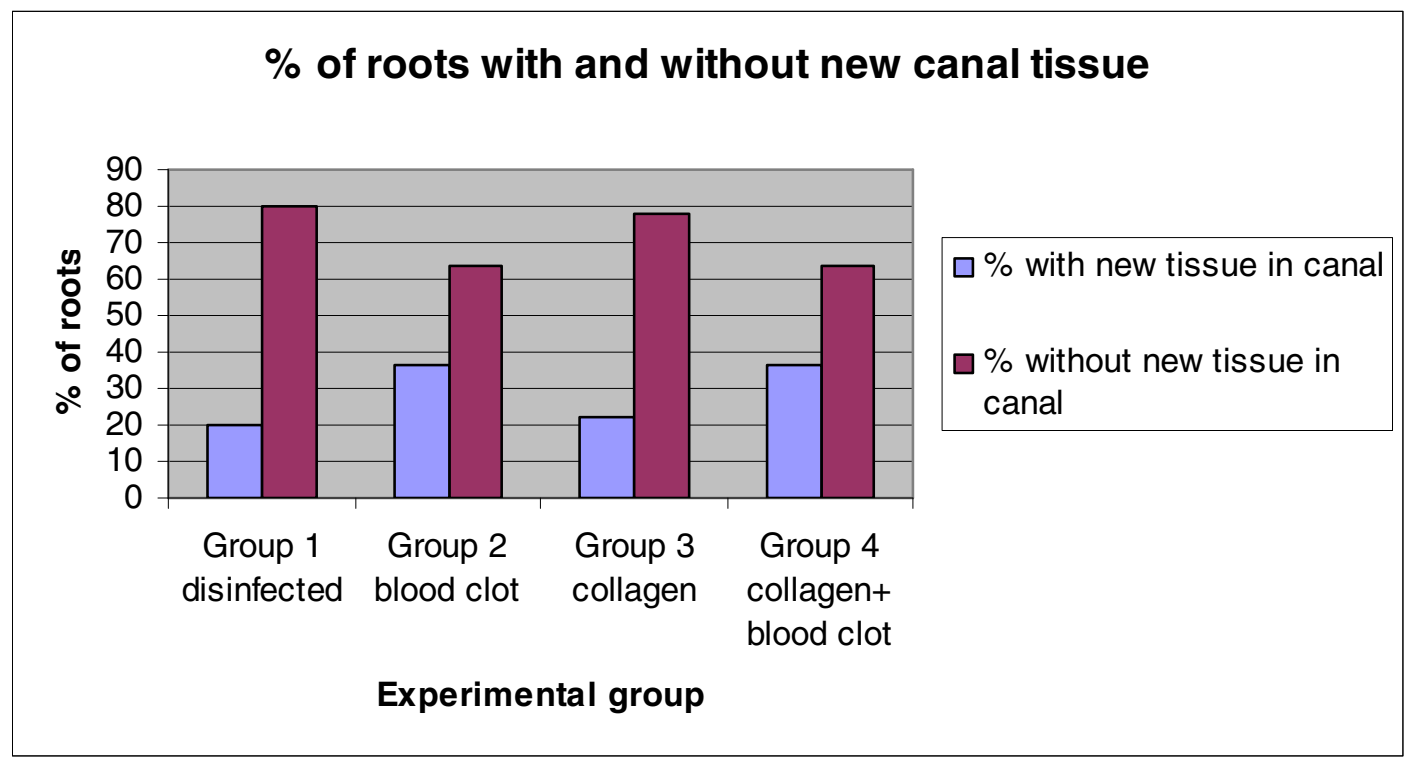

Fig 12. Percentage of roots in experimental groups with and without vital tissue within the canal space assessed histologically.

When comparing the histological evidence of vital tissue within the canal space with respect to the four experimental groups, it was evident that $29.3 \%$ of the roots overall from all groups combined showed histological evidence of vital tissue within the canal space. In groups 2 (infected $\rightarrow$ disinfected $\rightarrow$ blood clot) and 4 (infected $\rightarrow$ disinfected $\rightarrow$ collagen + blood clot), those including the use of a blood clot, more than $36 \%$ of the roots showed histological evidence of vital tissue within the canal space. Approximately $20 \%$ of the roots in groups 1 (infected $\rightarrow$ disinfected) and 3 (infected $\rightarrow$ disinfected $\rightarrow$ collagen) showed histological evidence of vital tissue in the canal spaces. 


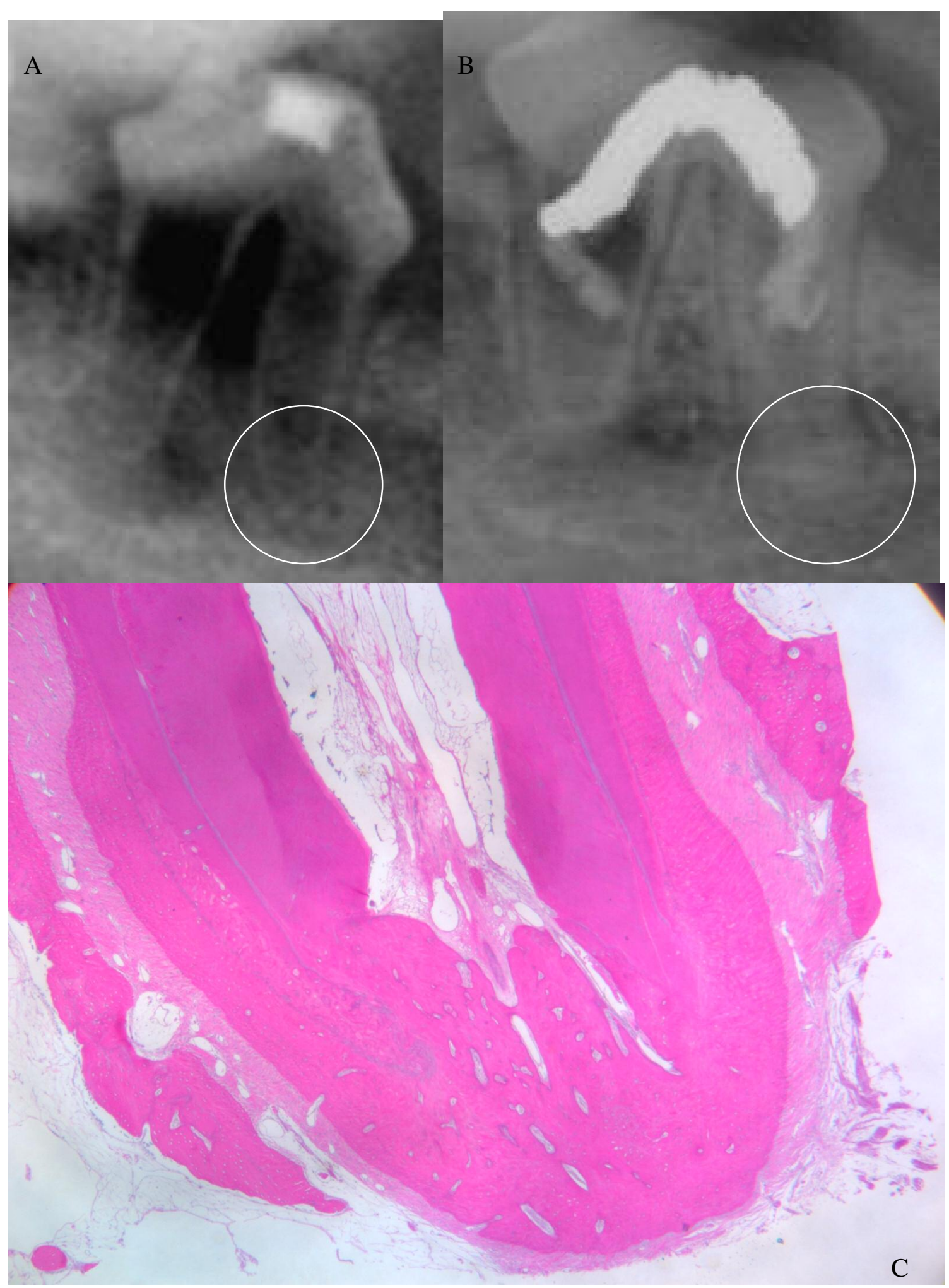

Fig 13. Tooth from group 1 (disinfected only) showing thickened root walls, apical development and healing of apical periodontitis. A) Pre-disinfection. B) Post-mortem. C) Histology (original magnification 2X). 


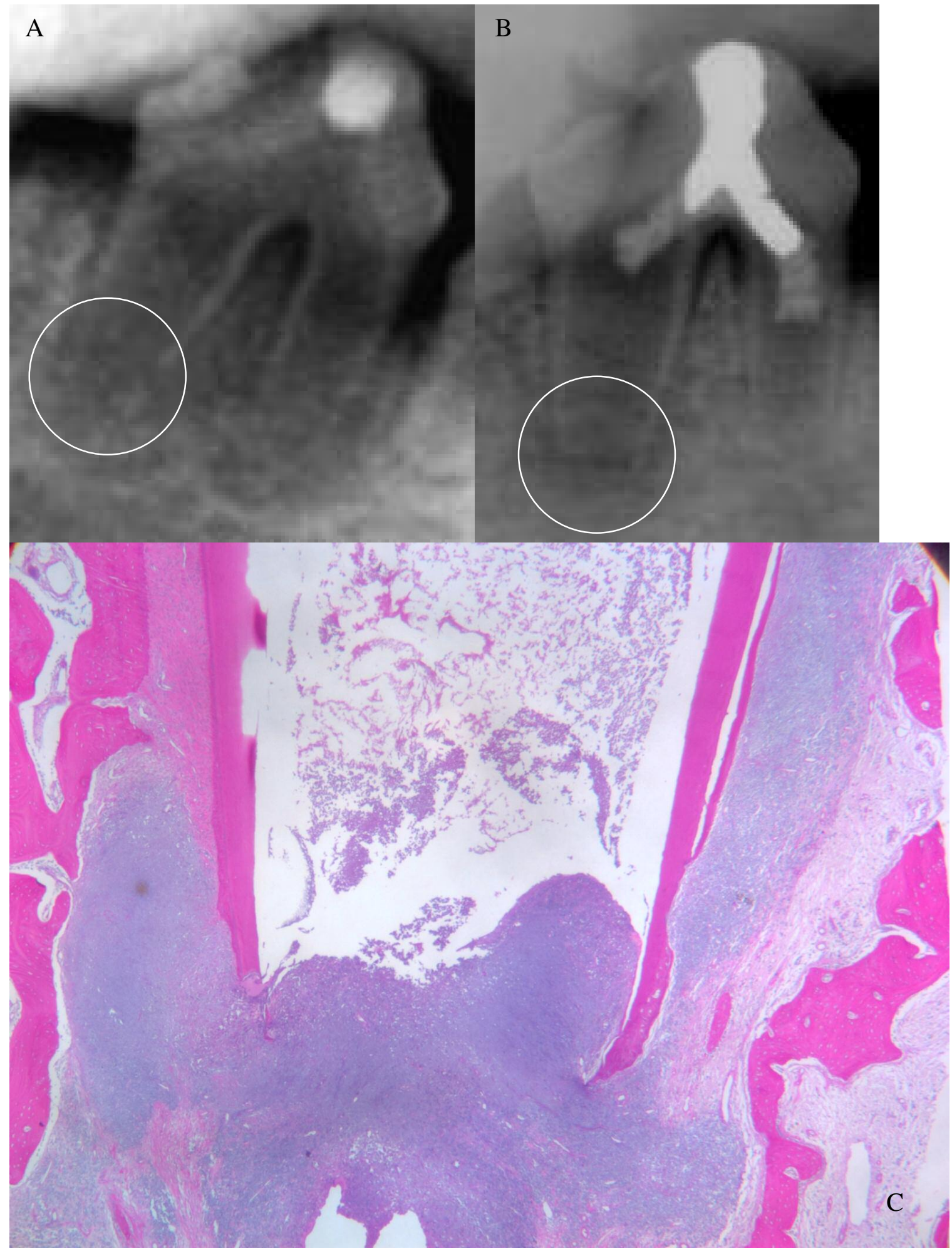

Fig 14. Tooth from group 1 (disinfected only) showing persistence of apical periodontitis, thin root walls and lack of development of apices. A) Pre-disinfection. B) Post-mortem. C) Histology (original magnification 2X). 


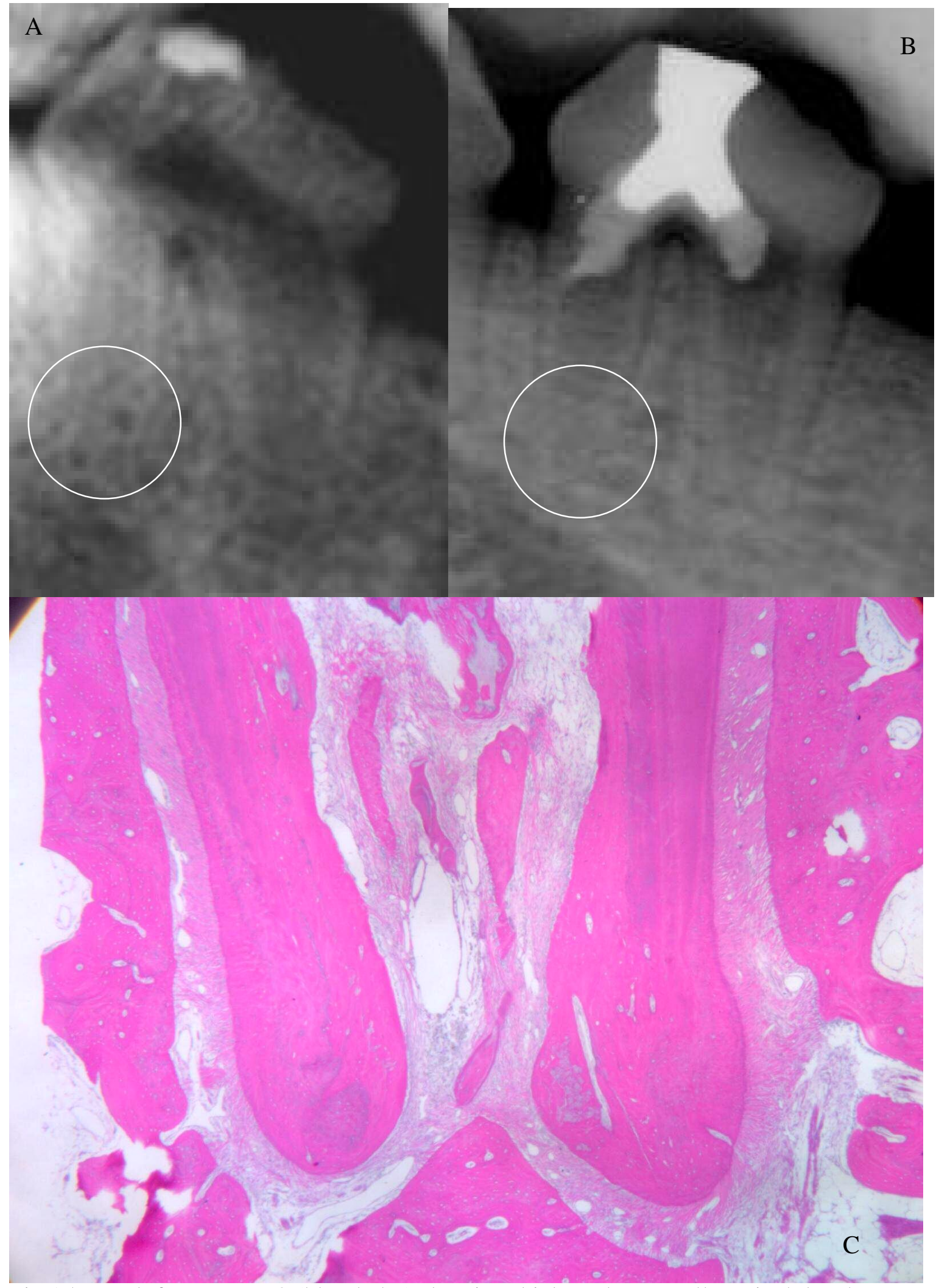

Fig 15. Tooth from group 2 (blood clot) showing thickened root walls, apical development and healing of apical periodontitis. A) Pre-disinfection. B) Post-mortem. C) Histology (original magnification $2 \mathrm{X}$ ). 


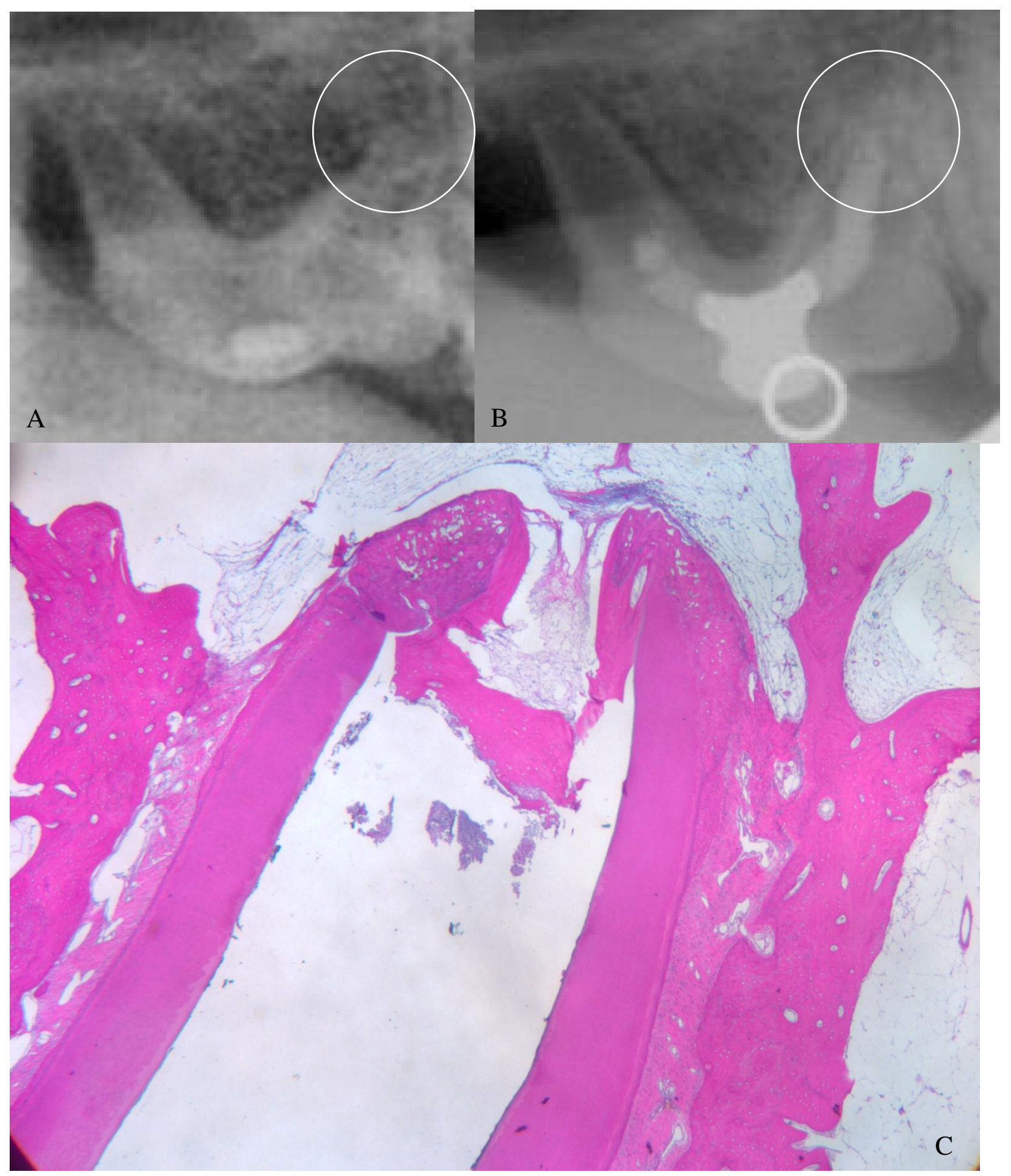

Fig 16. Tooth from group 2 (blood clot) showing apical development and ingrowth of new hard tissue. A) Pre-disinfection. B) Post-mortem. C) Histology (original magnification 2X). 


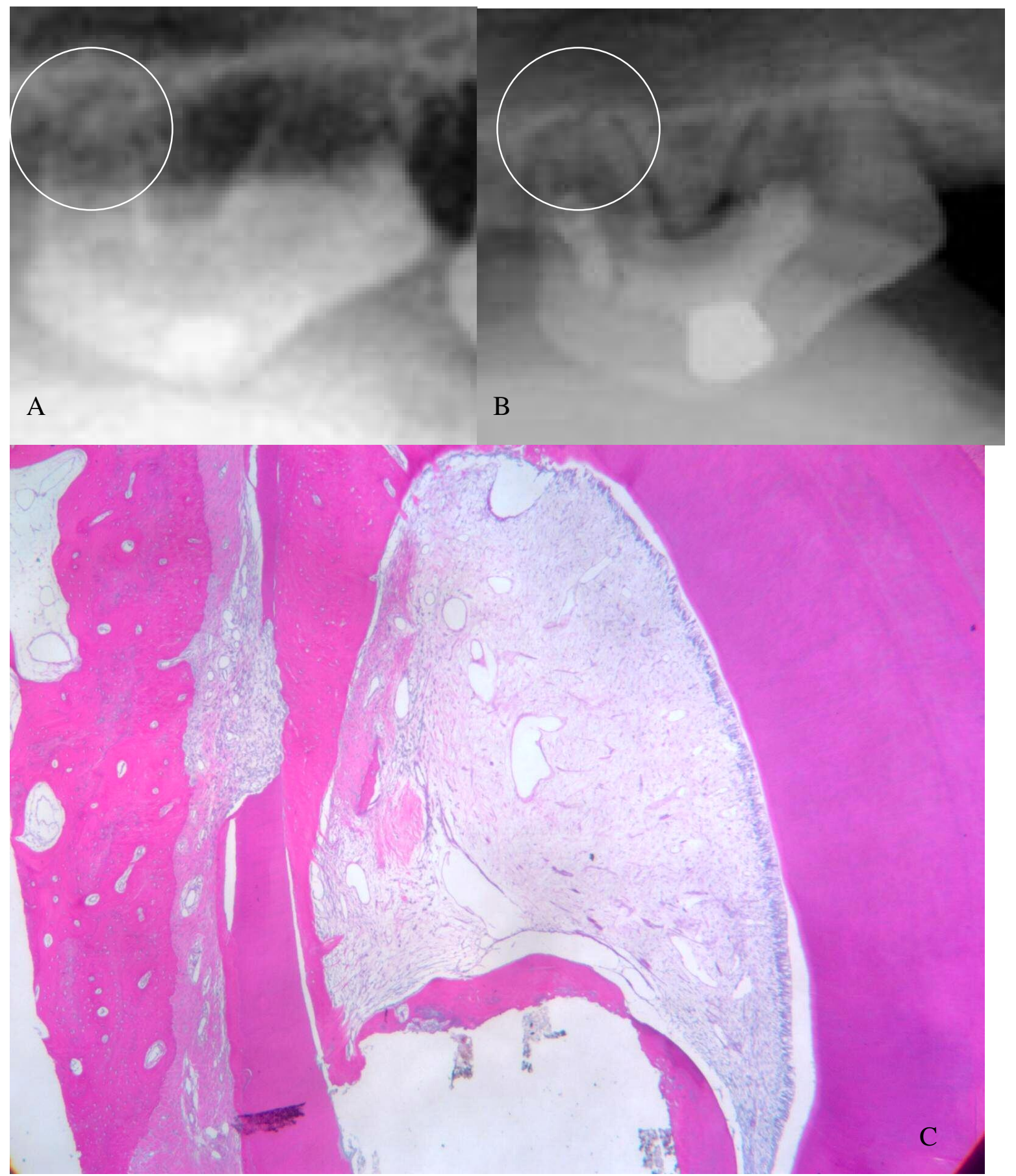

Fig 17. Tooth from group 2 (blood clot) showing apical development with normal pulp tissue separated from the root filling by hard tissue. A) Pre-disinfection. B) Post-mortem. C) Histology (original magnification 2X). 


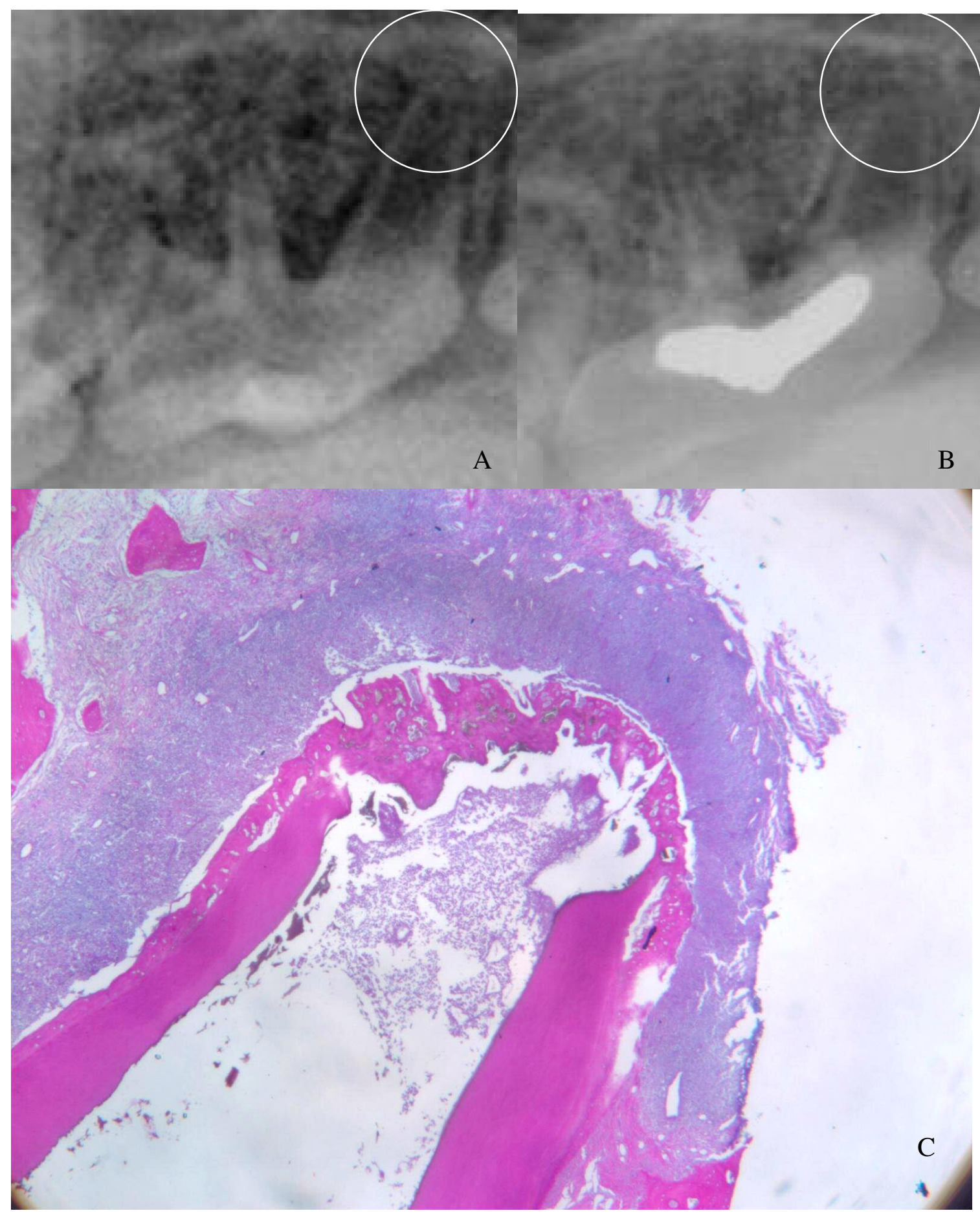

Fig 18. Tooth from group 3 (collagen only) showing apical hard tissue barrier. A) Predisinfection. B) Post-mortem. C) Histology (original magnification 2X). 


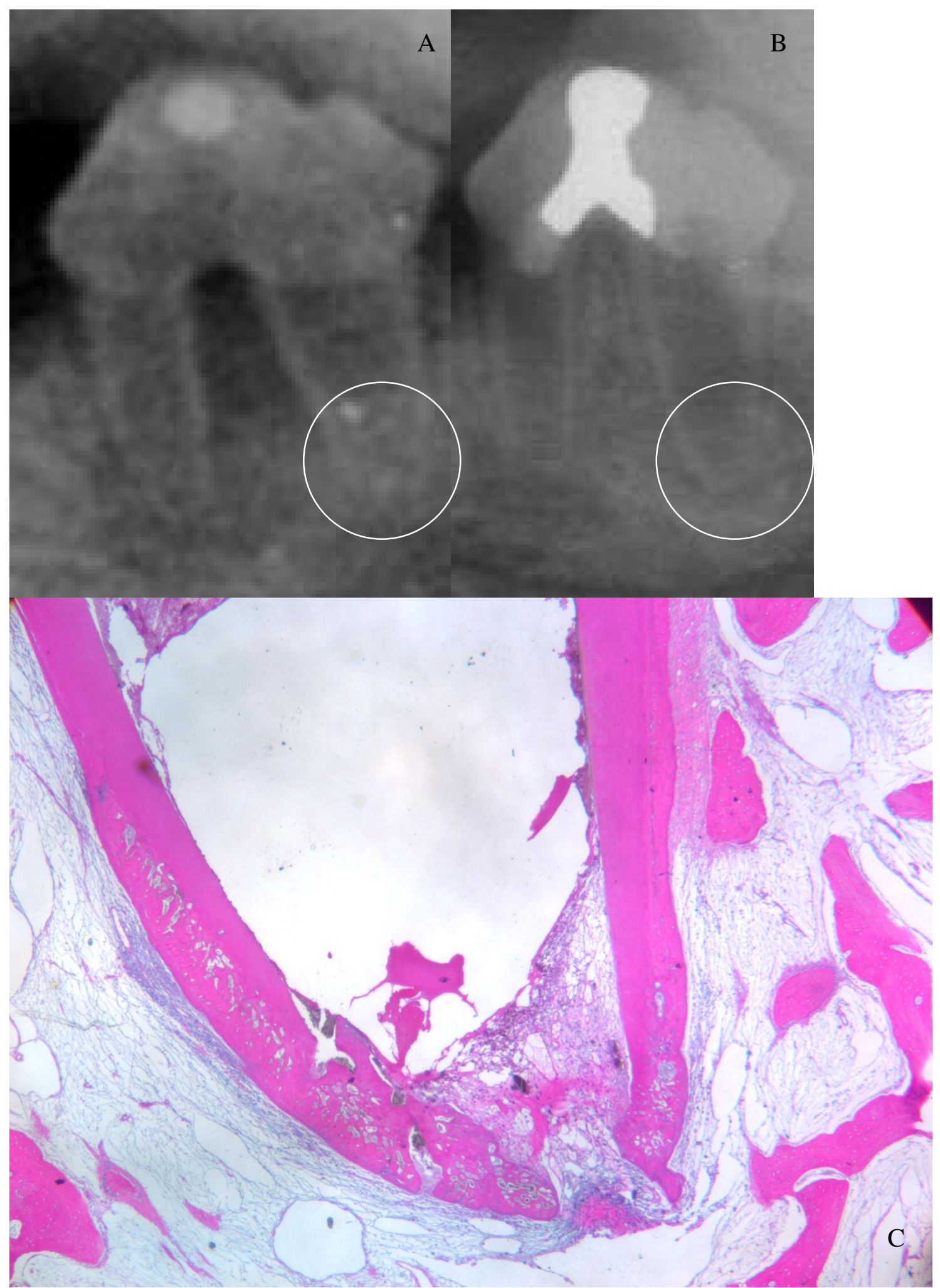

Fig 19. Tooth from group 4 (collagen + blood clot) showing apical closure with hard tissue. A) Pre-disinfection. B) Post-mortem. C) Histology (original magnification 2X). 


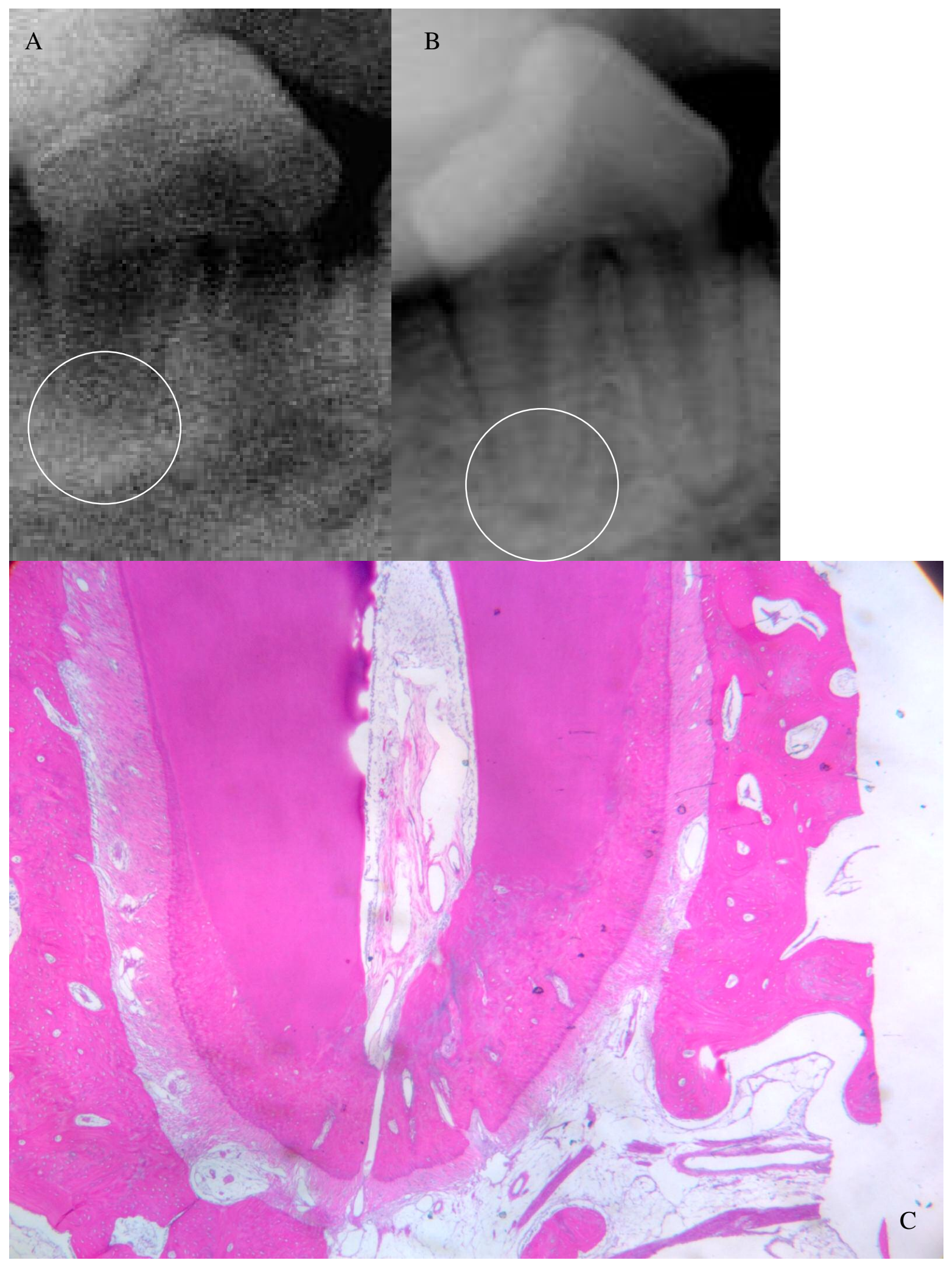

Fig 20. Tooth from group 5 (negative control) showing continued apical and radicular development with normal pulp tissue. A) Early stage. B) Post-mortem. C) Histology (original magnification $2 \mathrm{X}$ ). 


\section{DISCUSSION}

The results of this project showed very importantly that necrotic infected teeth that are disinfected by use of this triple antibiotic paste system can be revascularized with healthy new vital tissue. To our knowledge, this is the first such demonstration of this fact using a controlled trial in an animal model. This technique should be further studied in order to render it more predictable and it should be expanded by additional research to further increase its positive outcomes. Further research may include treatment of disinfected canals with specific growth factors to improve the revascularization outcomes to a higher level.

This project did not include a positive control group of teeth that were infected but not disinfected or treated further. The inclusion of such a group is not warranted, as historical controls have conclusively shown the outcome of such a group. Classical studies including Kakehashi et al (7) in rats and Moller et al (8) in monkeys included groups of teeth treated in this manner - auto-infected with oral bacteria and not disinfected. All of the teeth in these categories went on to have complete pulp necrosis and infection of the canal spaces with development of apical periodontitis. Histologically, all of these teeth developed periapical granulomas, with some eventually showing cystic changes.

None of the teeth that would have been treated in this manner (infected but not disinfected) would have been expected to show any positive changes with respect to the radiographic outcome measures (healing of apical periodontitis, thickening of root walls or apical closure) or histologic outcome measures (hard tissue deposition on internal root walls, apical closure or new tissue formation within the canals). For this reason, there was no need to include this category. It would not have been ethical or moral since the outcome was already known. 
Type I collagen was obtained from BD Biosciences (Bedford, Massachusetts). The collagen solution was produced from pepsinized rat tail tendon. This treatment removes the telopeptides (both $\mathrm{C}$ and $\mathrm{N}$ terminal non-helical domains) of type I collagen to aid in its solubility, and to reduce its antigenicity. This treatment allowed the use of this xenogenic material from rats in dogs, as it has been shown $(41,42)$ to be well-tolerated by host animals of different species in previous studies without induction of an antibody response.

The use of collagen as a scaffold or matrix for the ingrowth of tissue into root canals has been attempted by Nevins in previous studies (39-43). Nevins and co-workers have used collagen gels containing nucleation crystals for hydroxyapatite (calcium and phosphate), and have experimented with the use of cross-linked collagen gel to improve the handling characteristics and further reduce the antigenicity. The results of these studies show promise in aiding growth of tissue within the canal spaces; however, most of these studies were done on vital teeth with only partial pulpectomies or pulpotomies performed. In other words, these teeth likely still retained some vital tissue within the canal spaces. No new tissue would have had to grow into the canal spaces to replace the missing pulp, but the continued growth of the remaining tissue within the canals was improved with the use of their experimental gel. In their 1976 study (39) in which monkey teeth were left open to the oral cavity to allow autoinoculation, no numerical results are offered. Although the authors state that they saw positive results with many of the infected teeth revascularized, no numbers are provided in their report to allow the reader to make any unbiased objective evaluations of their findings. The difference between this study and those of Nevins is primarily in the presence of canal infection prior to disinfection and attempted pulp space revascularization. Further, our collagen solution did not include calcium or phosphate minerals. 


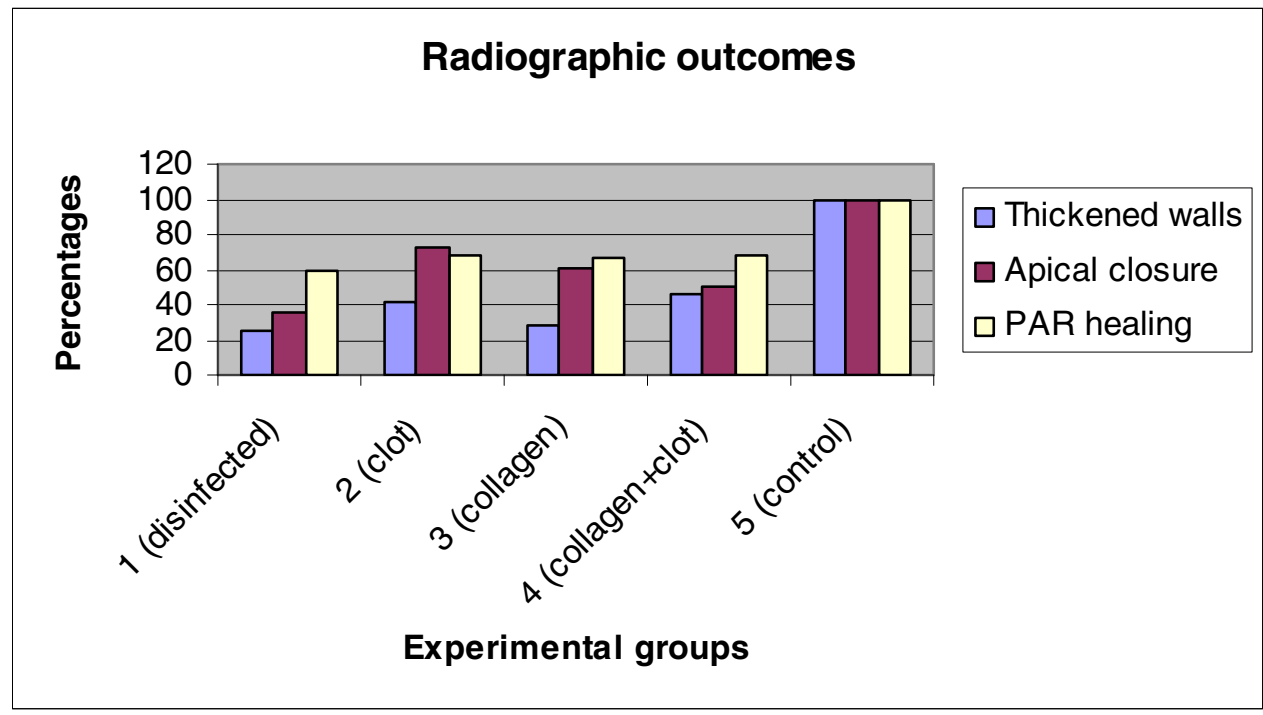

Fig 21. Percentages of roots in each experimental group showing positive outcomes measured radiographically.

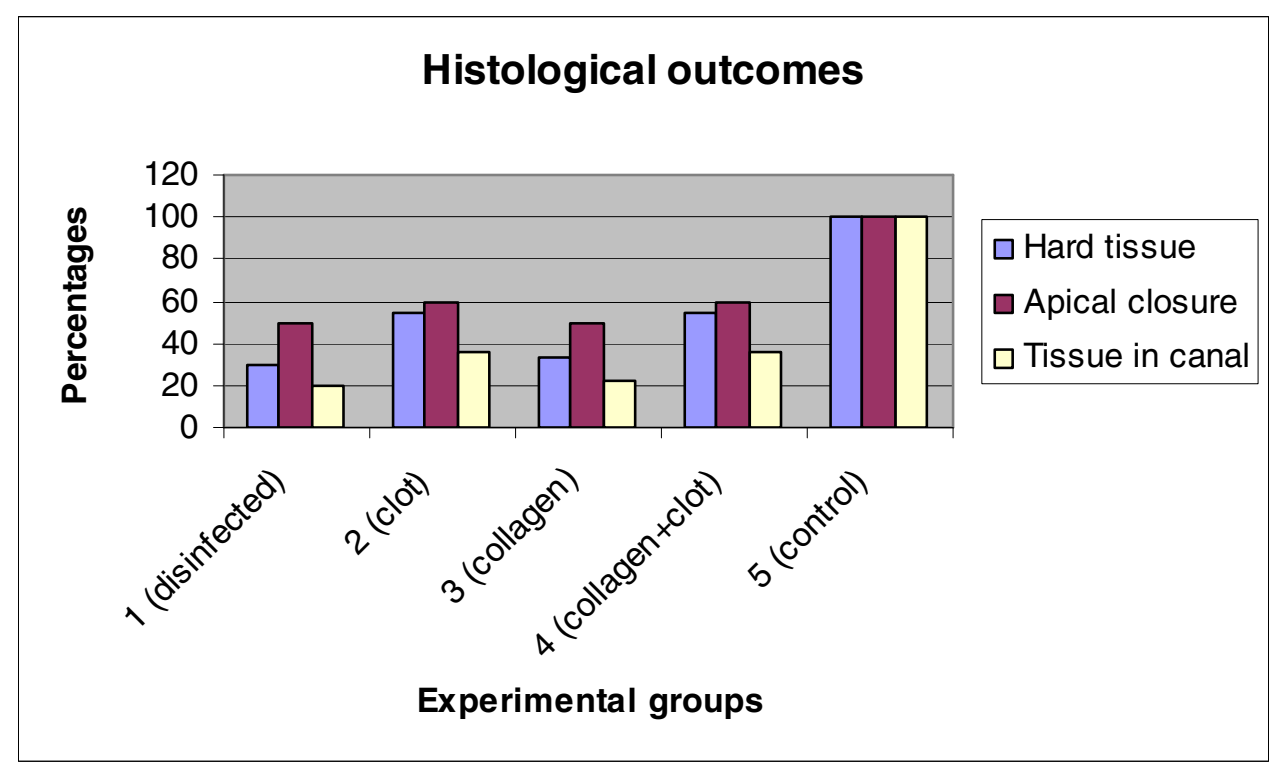

Fig 22. Percentages of roots in each experimental group showing positive outcomes measured histologically.

Although the results were not statistically significantly different between the experimental groups, it was evident from the results in this study that the experimental group containing the collagen solution alone (group 3) did not produce results as positive compared with the groups containing the blood clot (group 2 - infected $\rightarrow$ disinfected $\rightarrow$ blood clot or group 4 - 
infected $\rightarrow$ disinfected $\rightarrow$ collagen + blood clot $)$. The roots with the collagen solution alone (group 3) fared no better than the roots that were only disinfected (group 1). It is possible that the collagen solution alone (without the presence of a blood clot) prevented the ingrowth of any new tissue or progenitor cells from the periapical area. Although collagen solutions have been shown to be relatively non-antigenic (39-41), it is possible that the collagen solution was not beneficial for ingrowth of new tissue, or it may have even hindered the ingrowth of new tissue cells. Unless there was induction of bleeding from the periapex into the collagen solution at the time the collagen was applied into the canal space (as in roots in group 4), it may not have been possible for progenitor cells to invade the canal space since it was occupied by the collagen solution (as in roots in group 3 - infected $\rightarrow$ disinfected $\rightarrow$ collagen). The collagen solution may have solidified into a more gelatinous substance after time in the canal space. This may have prevented any new cells from entering the canal space from the periapical area if they had not been present before the collagen gelled. Even if the collagen solution did not become more gelatinous in time, its physical presence in the canal space may have been enough to keep out progenitor cells from the periapical area if they were not introduced along with blood from the trauma of the endodontic file inserted beyond the apical area at the time of collagen solution injection. Conversely, it is possible that the collagen solution was not viscous enough to have been retained in the canal space. It may simply have been too fluid and dispersed out of the open apex of the canals. This possible occurrence may better explain why the results of group 3 (infected $\rightarrow$ disinfected $\rightarrow$ collagen) often paralleled those of group 1 (infected $\rightarrow$ disinfected), because the canals in both groups may have actually been empty - devoid of any scaffold in the canal space. 
The inclusion of a blood clot has been debated in the literature in attempts at revascularization. Early studies by Nygaard-Ostby and Hjortdal (29) concluded that a blood clot did not improve revascularization in cases of complete canal debridement followed by partial filling with or without an induced blood clot in the unfilled portion of the canal. In these cases, the authors judged that the blood did improve the revascularization of the unfilled portion of the canal, but that their results were limited by infection of the canal space, since they did not use an intracanal medicament to aid in canal disinfection. In our material, disinfection of the canal spaces with the triple antibiotics may improve the outcome of revascularization despite previous infection. Because the triple antibiotic combination has been shown to be effective in disinfecting the canal spaces (36), revascularization should be expected on a more predictable basis. In our study, the inclusion of a blood clot, with or without the use of a collagen solution as a scaffold, improved the revascularization rate of the immature dog root canal systems after disinfection.

A 1971 study by Davis et al (31) with total pulpectomies and partial root fillings in dogs showed no benefit to the use of a blood clot. In their study, apical areas of the canals were enlarged greatly, allowing ingrowth of new tissue. They concluded that it was a large apical size that was more important than the inclusion of a blood clot in the unfilled portion of the canal to improve revascularization. Their material differs from that in our study as their teeth were vital at the time of pulp removal, while ours were necrotic and infected. We showed that the inclusion of a blood clot was important in improving revascularization of the unfilled portion of the canals after disinfection. It appears that in an un-infected canal, the inclusion of a blood clot is not beneficial in improving revascularization. 
A monkey study published in 1974 by Myers and Fountain (32) did not show any value to inclusion of a blood clot or blood substitutes in revascularization attempts in necrotic infected canals. The infected canals in their study were treated in one appointment with $5.25 \%$ sodium hypochlorite irrigation for disinfection along with apical enlargement prior to the placement of the blood or blood substitutes. However, no revascularization occurred in these cases. The failure of revascularization in this study may more likely be blamed on incomplete disinfection of the canal spaces, rather than on any negative effect of the blood or blood substitutes. Their results showed infection of the canal spaces with bacteria, as well as remaining necrotic debris despite the measures taken to disinfect the canals. However, there is strong evidence that single appointment endodontic treatment of necrotic infected canals using sodium hypochlorite without the use of an intracanal inter-appointment medicament (traditionally calcium hydroxide) will not render infected canals free of bacteria (10). Infected canals can be predictably disinfected by use of traditional techniques of calcium hydroxide inter-appointment intracanal medicament $(10,13)$, but this may kill the viable cells in the periapical area that would be otherwise available to re-populate the canal space (44). The triple antibiotic paste has also been shown to effectively reduce the bacterial load in infected immature canals without the use of mechanical instrumentation (36), and to preserve the vitality of the progenitor cells in the apical area for subsequent revascularization (26). Our results showed that the blood clot was beneficial in improving revascularization after disinfection with the triple antibiotics, in contrast with the results of the Myers and Fountain study (32).

A 1978 report by Horsted and Nygaard-Ostby (30) showed that there was no benefit to a blood clot in an experimental study of revascularization in human teeth with complete pulp 
removal and partial root fillings. In their study of vital teeth, canals treated with and without a blood clot showed evidence of revascularization in the unfilled portion of the canals. These results are in contrast to our findings, which showed that a blood clot was beneficial in improving the revascularization rate in immature teeth that had been previously infected prior to disinfection with the triple antibiotic mix. In our material, the canals that were disinfected but left empty (group 1) had less revascularization than those that included use of a blood clot after disinfection (groups 2 and 4), regardless of the presence of a collagen scaffold. The main difference between our study and that of Horsted and Nygaard-Ostby was the lack of initial canal infection in their material, while the experimental canals in our study were all infected at the time of disinfection. In addition, in the teeth in the study by Horsted and Nygaard-Ostby where attempts were made to prevent a blood clot from forming, it is highly likely that a blood clot formed in the unfilled terminal portions of the canals after they filled them short of the apical foramen, thus influencing their results by negating the group without a blood clot. Although a blood clot may not improve revascularization in vital teeth, it appears, from our material, to improve revascularization in previously infected canals after disinfection.

The roots treated with a blood clot (whether alone - group 2 - or in combination with the collagen solution - group 4) in this study had similar results in most outcome categories. In most categories, groups 1 (no blood clot - infected $\rightarrow$ disinfected) and 3 (no blood clot infected $\rightarrow$ disinfected $\rightarrow$ collagen) had similar outcomes, generally lower than those for groups 2 (infected $\rightarrow$ disinfected $\rightarrow$ blood clot) and 4 (infected $\rightarrow$ disinfected $\rightarrow$ collagen + blood clot). From these results, it can be said that the use of the collagen solution did not aid in the revascularization of disinfected immature root canals in dog teeth. The collagen 
solution on its own (group 3) was no better than the control group (group 1 - infected $\rightarrow$ disinfected) which had only been disinfected and had no further treatment of the canal space.

The use of a blood clot in the canal spaces following disinfection with the triple antibiotic paste of metronidazole, minocycline and ciprofloxacin (whether alone - group 2 - or in combination with a collagen solution - group 4) had better results than the groups without the use of a blood clot (group $1-$ infected $\rightarrow$ disinfected - and group $3-$ infected $\rightarrow$ disinfected $\rightarrow$ collagen). The blood clot may serve as a scaffold for ingrowth of new tissue, since it consists of fibrous proteins of cross-linked fibrin. It may simply serve as a pathway for the migration of cells $(48,49)$ including macrophages and fibroblasts from the periapical area, even if they did not initially travel into the root canal spaces with the blood at the time that the bleeding was induced. However, a blood clot does not only consist of an inactive scaffold. Its cells contain many growth and differentiation factors important in the wound healing process (50-52). A report by Maeda and others in 2004 (50) reported that human periapical granulation tissue contains osteogenic cells. Human fibroblastic cells were isolated from granulation tissue obtained from surgical specimens of human periapical lesions refractory to conventional endodontic treatment. In vitro, these cells were shown to upregulate gene expression involved in healing and bone formation. It would be this very granulation tissue or early healing tissue that was the source of the bleeding induced into the canal spaces in our study. It is quite conceivable that the blood would have brought these reparative cells along with it when an endodontic file was inserted into the periapical granulation tissue beyond the terminus of the root canals.

Platelets make up a large part of a blood clot. Platelets contain and actively secrete seven active growth factors (51) including three isomers of platelet derived growth factor 
(PDGF $\alpha \alpha$, PDGF $\beta \beta$ and PDGF $\alpha \beta$ ), two of the numerous transforming growth factors- $\beta$ (TGF $\beta 1$ and TGF $\beta 2$ ), vascular endothelial growth factor (VEGF), and epithelial growth factor (EGF). Proteins in blood including fibrin, fibronectin and vitronectin also act as cell adhesion molecules for osteoconduction and as a matrix for bone, connective tissue and epithelial cell migration during wound healing (51). By inducing these proteins and growth factors to enter the disinfected root canal spaces, the blood clot acted not only as a scaffold, but also as a repository of tissue healing factors that improved the development of new hard and soft tissue within the canal spaces, as well as increasing deposition of new hard tissue on the internal root canal walls in this study. Degranulation of platelets releases synthesized and pre-packaged growth factors from their $\alpha$ granules. The stimulus for this degranulation of platelets is the initiation of the clotting process, with the active secretion of these factors beginning within ten minutes of clot initiation, and being more than $95 \%$ complete within one hour of initiation of clotting (51). Adult mesenchymal stem cells, osteoblasts, fibroblasts, endothelial cells and epithelial cells express cell membrane receptors to the growth factors found in platelets, which leads to cell proliferation and matrix production and continues the healing process. It is likely that the physical trauma of using an endodontic file to cause bleeding of the apical tissues into the canal space also disrupted the periapical tissues (including the periodontal ligament tissues), which led to passage of their cells into the empty canal spaces. These cells are the likely source of the progenitor cells (PDL and granulation tissue cells) that were available for formation of new hard and soft tissue that was stimulated by the growth and differentiation factors present in and released from the blood clot.

The poorer outcomes seen with the collagen solution (group 3) employed in this study as a simple scaffold to aid ingrowth of new tissue lend further support to the fact that the blood 
clot acts as more than an empty scaffold. If the clot acted only as a scaffold, the collagen solution alone (group 3) should have performed as well as the blood clot alone (group 2). However, given that the roots in group 2 (blood clot) had greater positive outcomes suggests that the blood clot serves other functions besides passive scaffold properties. The blood clot contains the growth and differentiation factors that improved the revascularization potential of the roots that were treated with a blood clot (groups 2 and 4). These factors served to bolster the healing potential of the cells that were able to migrate in along the protein fibers of the scaffold of the clot. These factors were lacking in the roots treated with only the collagen (group 3). Even if progenitor cells successfully migrated in along the collagen scaffold into the canal spaces in roots in group 3, they lacked the stimuli provided by the components of the blood clot in groups 2 (infected $\rightarrow$ disinfected $\rightarrow$ blood clot) and 4 (infected $\rightarrow$ disinfected $\rightarrow$ collagen + blood clot). Without the growth and differentiation factors provided by the blood clot after disinfection, there were poorer results ofthe surrogate outcome measures used to assess revascularization of the canal spaces (thickening of root canal walls by deposition of new hard tissue and ingrowth of new healthy hard or soft tissue in the lumen).

In many of the roots in this study, hard tissue deposition was evident at the apices, regardless of the ingrowth of new tissue within the canal spaces, and also irrespective of the presence or absence of inflammatory tissue in the periapical area. It is possible that the early formation of an apical hard tissue barrier may have precluded later ingrowth into, or the development and maturation of, new tissue in the canal spaces.

In the clinical situation of a pulpless tooth with an open apex, the traditional treatment technique is that of calcium hydroxide apexification. Calcium hydroxide is placed directly 
against vital tissue present at the periradicular area. $\mathrm{By}$ an increase in $\mathrm{pH}$, and by exclusion of bacteria (via the calcium hydroxide), an environment is created whereby hard tissue is laid down to close off the open apex (17). In the situation in this experiment, it is possible that the exclusion of bacteria (via the use of the triple antibiotics) (36) created an environment for hard tissue formation to close off the open apex. Cox et al (21) showed that if pulpal soft tissue is maintained bacteria free (or rendered bacteria free) a hard tissue barrier may form from vital tissue in the pulp space. Extrapolating this to the situation at the apex in this study, a hard tissue barrier may also be created by the vital soft tissues present in the periradicular location if bacteria are excluded from this area. This may be why there was not new tissue ingrowth in all of the canals. Many canals had hard tissue barriers formed at the apex, which would have precluded/prevented ingrowth of new vital tissue. It is not the calcium hydroxide in the apexification procedure that is necessary to induce the formation of a hard tissue barrier, but the absence of bacteria that leads to hard tissue formation $(7,19-21)$. This is why it was possible to induce an apical hard tissue barrier in roots that were disinfected with the triple antibiotics without any use of calcium hydroxide.

Cvek and others (26) showed that topical use of antibiotics is not harmful to human periodontal cells. In an experimental avulsion study in monkeys, topical doxycycline improved the revascularization rate by preventing the infection of the necrotic pulp with oral bacteria, while allowing viable cells in the apical area to re-populate the canal space. This is in contrast with the limited necrosis of vital cells by the topical application of calcium hydroxide (44) in the traditional technique of calcium hydroxide apexification of a pulpless open apex tooth. By the use of topical antibiotics in this study, the vitality of cells in the 
periapical area was preserved, allowing them to migrate into the canal space and revascularize it.

\section{Radiographic Analyses}

\section{PAR (Periapical radiolucencies)}

Although there were no statistical differences between the four experimental groups for healing of apical periodontitis judged radiographically, there was radiographic evidence of healed apical periodontitis among all of the experimental groups that were disinfected with the triple antibiotic paste (metronidazole, minocycline and ciprofloxacin). This supports the findings of Windley et al (36) that the use of the triple antibiotic paste causes a significant reduction in bacteria in experimentally infected canals of immature dog teeth. It should be noted further that, had there been a group of positive controls that were simply infected and not disinfected or treated further, historical evidence $(7,8)$ shows that $100 \%$ of those teeth would have remained infected and periapical radiolucencies would have persisted. Also, it should be noted that the time frame of this study may simply not have been long enough for complete radiographic evidence of healing of periapical radiolucencies. Strindberg (53) showed that it may take up to four years for complete healing of apical periodontitis lesions; before which, failure should not be assessed. However, $65.9 \%$ of the infected roots in groups $1-4$ (previously infected canals) showed healing of existing periapical radiolucencies (with near equal outcomes in each group) after treatment with the triple antibiotic paste, indicating 
that the use of this material can be relied upon to consistently render infected canals effectively free of bacteria.

\section{Thickening of radicular walls}

Although there were no statistical differences between the four experimental groups with respect to thickening of radicular dentin walls seen radiographically, there was radiographic evidence of continued thickening of radicular dentin walls among all of the experimental groups that were disinfected with the triple antibiotic paste (metronidazole, minocycline and ciprofloxacin). Had there been a group of positive controls that were simply infected and not disinfected or treated further, historical evidence $(7,8)$ shows that $100 \%$ of those teeth would not have had continued thickening of radicular dentin walls. In this study, $35.4 \%$ of the roots in groups $1-4$ (previously infected canals) showed some continued thickening of root walls judged radiographically after treatment with the triple antibiotic paste. This outcome was due to ingrowth of progenitor cells from the periapical area, as the pulps in these teeth were all necrotic and infected prior to disinfection with the triple antibiotic paste. This was not due simply to the disinfection, but was evidence of successful revascularization at least in part, as the new hard tissue was produced by new cells that grew in to repopulate the canal space.

There was a trend such that tripling the numbers but maintaining the same proportions would have given a statistically significant difference $(p=0.03)$ between the experimental groups with respect to thickening of radicular walls judged radiographically. The Chi squared tests between the individual groups (groups $1-4$ ) after tripling the numbers and maintaining the proportions (with one degree of freedom) showed significantly thicker radicular walls in 
group 4 (infected $\rightarrow$ disinfected $\rightarrow$ collagen + blood clot) than group 1 (infected $\rightarrow$

disinfected $)(p=0.02)$, and group 4 (infected $\rightarrow$ disinfected $\rightarrow$ collagen + blood clot $)$ more than group 3 (infected $\rightarrow$ disinfected $\rightarrow$ collagen) $(\mathrm{p}=0.046)$. This is further evidence that the collagen solution did not provide any advantages in the stimulation of the revascularization process. It was the inclusion of the blood clot (and its constituent growth and differentiation factors) that was important for successful revascularization after disinfection.

\section{Apical closure}

Although the only statistical difference between the four experimental groups with respect to radiographic evidence of apical closure was between groups 1 and $2(p=0.01)$, with group 2 (infected $\rightarrow$ disinfected $\rightarrow$ blood clot) showing more apical closure than group 1 (infected $\rightarrow$ disinfected), there was radiographic evidence of apical closure among all of the experimentally infected groups (groups $1-4$ ) that were disinfected with the triple antibiotic paste (metronidazole, minocycline and ciprofloxacin). If there had been a group of positive controls that were infected and not disinfected or treated further, historical evidence $(7,8)$ shows that $100 \%$ of those teeth would not have had apical closure. In this material, $54.9 \%$ of the roots in the experimental groups (groups $1-4$ ) showed radiographic evidence of apical closure (with approximately equal outcomes in each group). This may not be due to revascularization, however. In some cases, the root apices did not develop a physiologic closure accompanied by further thickening and development of the root walls and normal tapering closure of the apex, but rather developed a hard tissue barrier without further 
development of the radicular dentin walls - sometimes even in the presence of inflammatory tissue in the periapical area. This type of apical hard tissue barrier was due to the disinfection of the canal spaces by the triple antibiotic paste, allowing development of a hard tissue barrier in the absence of bacteria $(7,21)$ and was not necessarily the result of successful revascularization. For successful revascularization to have occurred there would have had to have been further thickening of the apical root walls and a normal physiologic tapered formation of the root apex, which was an outcome seen in some of the roots in this study. No pattern was seen among the groups (groups 1 -4) with respect to apical closure judged radiographically, as this outcome was due to disinfection, which was applied to all experimental groups equally. Apical closure was generally not due to further treatment of the roots (blood clot and/or collagen application to the canal spaces), but was due to disinfection.

\section{Histological Analyses}

\section{Hard tissue deposition on radicular dentin walls}

Although there were no statistical differences between the four experimental groups regarding histological evidence of new hard tissue deposition on internal root walls, there was histological evidence of hard tissue deposition on internal root dentin walls among all of the experimental groups (groups $1-4$ ) that were disinfected with the triple antibiotic paste (metronidazole, minocycline and ciprofloxacin). It should be noted further that, had there been a group of positive controls that were simply infected and not disinfected or treated further, historical evidence $(7,8)$ shows that $100 \%$ of those teeth would not have had 
histological evidence of hard tissue deposition on internal root dentin walls. In this study, $43.9 \%$ of the experimental roots showed histological evidence of hard tissue deposition on the internal dentin root walls. Although some canals only showed thickened root walls and a lack of new vital tissue in the canal space, some measure of successful revascularization was achieved in these cases as evidenced by new hard tissue deposition. It is possible that the hard tissue deposition stopped and new tissue formation in the pulp space did not occur in these cases because the new ingrowing cells were fragile and did not survive for a long duration in the canal spaces. They may have only been viable for a short time, laying down some hard tissue on the internal root canal walls prior to their death. Another possible reason for the presence of hard tissue deposition in the absence of new vital tissue in the canal lumen may be the limited space available in some canals when the coronal restoration was placed too far apically in the canal space. The physical presence of the coronal restoration (mineral trioxide aggregate and/or silver amalgam) too far apically may have precluded the formation of extensive deposits of new hard tissue on the internal canal walls, and any significant amounts of new tissue in the canal lumen proper.

New hard tissue deposited on the internal root canal walls is the histologic measure that corresponds to the radiographic measure of thickening of root walls. The percentage of roots in all four experimental groups (groups 1 - 4) that exhibited radiographic evidence $(35.4 \%)$ of continued root wall thickening was lower than the corresponding number of roots seen histologically (43.9\%) to have hard tissue deposited on the internal canal walls. This is in accordance with the fact that the hard tissue may not have been thick enough at the time of evaluation to be seen radiographically, while it was seen histologically. Perhaps with a longer observation period prior to sacrifice of the animals, there would have been a higher 
percentage of roots seen radiographically to demonstrate thickened root canal walls, which would have paralleled more closely the situation seen histologically, which is a more sensitive outcome measure.

There was a trend such that doubling the numbers but maintaining the same proportions would have given a statistically significant difference $(p=0.03)$ between the experimental groups with respect to hard tissue on the internal radicular dentin walls. The Chi squared tests between the individual groups (groups $1-4$ ) after doubling the numbers and maintaining the proportions (with one degree of freedom) showed significantly more hard tissue on the walls in group 2 (infected $\rightarrow$ disinfected $\rightarrow$ blood clot) than group 1 (infected $\rightarrow$ disinfected) $(\mathrm{p}=$ 0.02), and group 4 (infected $\rightarrow$ disinfected $\rightarrow$ collagen + blood clot) more than group 1 (infected $\rightarrow$ disinfected) $(\mathrm{p}=0.02)$. Although these numerical results in this study were not significant, the trend again underscores the fact that the groups that employed the use of the blood clot (with or without the inclusion of the collagen solution) after disinfection had better outcomes than those roots that did not include use of a blood clot in the canal space. It is the inclusion of the blood clot (and its constituents) that is important for successful revascularization after disinfection. The presence of new hard tissue deposited on the internal root canal walls was improved by inclusion of a blood clot after disinfection.

\section{Apical closure}

Even though there were no statistical differences between the four experimental groups (groups 1 -4) for apical closure seen histologically, there was histological evidence of apical closure among all of the experimental groups (groups $1-4$ ) that were disinfected with the 
triple antibiotic paste (metronidazole, minocycline and ciprofloxacin). Had there been a group of positive controls that were simply infected and not disinfected or treated further, historical evidence $(7,8)$ shows that $100 \%$ of those teeth would not have had histological evidence of apical closure. The results of this study showed that $54.9 \%$ of th roots in the experimental groups (groups 1 - 4) showed histological evidence of apical closure, sometimes even in the presence of periapical inflammation. This outcome is the same result as the radiographic outcome of apical closure (54.9\%). Again, this result does not necessarily represent revascularization. It may simply be a measure of disinfection, which will lead to hard tissue barrier formation in the absence of bacteria $(7,21)$ to close off the open apex of the canal. A hard tissue barrier formed in many cases without corresponding thickening of root canal walls, pointing to the fact that this was due to canal space disinfection rather than revascularization. However, some roots also displayed evidence of revascularization noted by canal wall thickening and normal physiologic apical formation along with hard tissue closure.

Although group 2 (infected $\rightarrow$ disinfected $\rightarrow$ blood clot) and group 4 (infected $\rightarrow$ disinfected $\rightarrow$ collagen + blood clot) showed marginally better outcomes with respect to histological apical closure than group 1 (infected $\rightarrow$ disinfected) and group 3 (infected $\rightarrow$ disinfected $\rightarrow$ collagen), all four experimental groups (groups $1-4$ ) were generally equal in this regard. This is because disinfection with the triple antibiotic paste was applied uniformly to all of the roots in all four of these experimental groups. The apical closure was not due to subsequent treatment after disinfection (blood clot and/or collagen solution application to the canal spaces), but was due to the antibiotic disinfection itself. 


\section{Vital tissue within canal spaces}

No statistical differences were seen between the four experimental groups (groups 1 -4)

for the presence of new vital tissue within the canal spaces; however, there was histological evidence of vital tissue within the canal spaces among all of the experimental groups (groups $1-4)$ that were disinfected with the triple antibiotic paste (metronidazole, minocycline and ciprofloxacin). If there had been a group of positive controls that were simply infected and not disinfected or treated further, historical evidence $(7,8)$ shows that $100 \%$ of those teeth would not have had histological evidence of vital tissue within the canal space. In this study, the roots in groups $1-4$ showed $29.3 \%$ with healthy new tissue within the canal spaces after disinfection with the triple antibiotics. All of these groups of infected canals performed better after disinfection than if there had been no disinfection, regardless of the presence or absence of a blood clot or collagen scaffold in the lumen. This is a very significant outcome.

Although it seems to be a minimal percentage of positive results, it highlights the fact that this protocol was able to render previously infected canals effectively bacteria free (36) and allow ingrowth of new vital tissue into the canal spaces. Traditional treatment techniques for an immature tooth with a necrotic infected pulp space, an open apex and thin root walls do not involve any attempts at further physiologic development of the tooth. With this protocol, it was possible to induce pulp space revascularization with new vital tissue. Although the tissue may not be pulp tissue proper, it is vital tissue that does not need to be removed from the canal space. It can remain in the canal space indefinitely and can be expected to provide thickening and consequent strengthening of root canal walls to prevent future fracture. In addition, this new tissue can provide for physiologic development of the apices so that if 
future endodontic treatment does ever become necessary, a more successful outcome can be expected since confinement of the root filling within the canal space can be expected to be more readily achievable than with an open apex.

The histological outcome of new vital tissue within the canal lumen also showed more positive outcomes for roots from group 2 (infected $\rightarrow$ disinfected $\rightarrow$ blood clot) and group 4 (infected $\rightarrow$ disinfected $\rightarrow$ collagen + blood clot) compared with group 1 (infected $\rightarrow$ disinfected) and group 3 (infected $\rightarrow$ disinfected $\rightarrow$ collagen). This again denotes the importance of inclusion of a blood clot to improve the chances of revascularization in previously infected canals that are disinfected with the triple antibiotic paste.

Kling et al (22) found 18\% revascularization in 154 immature human avulsed teeth that were replanted in their sockets. Ebeleseder et al (24), in a retrospective study, reported approximately a $30-40 \%$ chance of pulpal revascularization in replanted avulsed immature permanent human teeth. In both of these reports, the successfully revascularized teeth were not previously infected. They were only necrotic based on the severance of the pulpal blood supply at the time of avulsion, but the canals remained free of bacteria. The material from our study shows that it is possible to render infected canals to a neutral starting point via treatment with the triple antibiotic paste. By this method, it was possible to allow $29.3 \%$ of the previously infected roots to successfully revascularize with vital tissue. This is higher than the results in Kling's avulsion study, but lower than those of Ebeleseder's retrospective report, both of which deal with revascularization of uninfected necrotic avulsed teeth. In the material in Kling's and Ebeleseder's reports, the teeth were not infected like those in this study. Our result is a significant development in the future treatment of necrotic immature teeth with open apices. 
In general, there was a trend toward positive outcomes in this study that would have led to statistical significance with larger groups. If the resultant numbers had been increased (in some cases doubled and in some cases tripled), but the proportions maintained, there would have been a statistically significant difference between the groups, showing a more positive result for those categories that included a blood clot in the treated canals. Again, this points to the fact that the blood clot was important in improving revascularization outcomes after disinfection of infected canals with the triple antibiotics. The study was underpowered with respect to numbers of animals/roots. However, this was a pilot project to determine the usefulness of this treatment modality/technique as a feasible option for treatment of immature necrotic teeth with apical periodontitis. The results of this study shed light on the possibility for successful revascularization of necrotic infected immature teeth with open apices after disinfection.

Another limitation of the study was the limited time available to follow the animals. Had there been a longer observation period, perhaps there would have been more ingrowth of tissue in canals where there was none at the final time point. In addition, more time might have allowed more apical closure or development, more thickening of root walls (histologically and radiographically) and further healing of apical periodontitis lesions.

\section{CONCLUSIONS}

Revascularization of necrotic, infected, immature teeth is possible after disinfection with a triple antibiotic paste of metronidazole, minocycline and ciprofloxacin and should be studied 
further and expanded with intracanal application of additional growth and differentiation factors as a viable treatment alternative for teeth with this clinical diagnosis.

A collagen solution did not aid revascularization of infected immature dog root canal systems after disinfection with a triple antibiotic paste of metronidazole, minocycline and ciprofloxacin.

Inclusion of a blood clot seemed to improve the outcomes of attempted revascularization after disinfection of necrotic infected immature dog root canal systems with the triple antibiotic combination. 


\section{REFERENCES}

1. Andreasen JO, Ravn JJ. Epidemiology of Traumatic Dental Injuries to Primary and Permanent Teeth in a Danish Population Sample. Int J Oral Surg. 1972;1(5):235-9.

2. Bastone EB, Freer TJ, McNamara JR. Epidemiology of Dental Trauma: A Review of the Literature. Aust Dent J. 2000 Mar;45(1):2-9.

3. Andreasen FM, Pedersen BV. Prognosis of Luxated Permanent Teeth--the Development of Pulp Necrosis. Endod Dent Traumatol. 1985 Dec;1(6):207-20.

4. Olgart L, Brannstrom M, Johnson G. Invasion of Bacteria into Dentinal Tubules. Experiments in Vivo and in Vitro. Acta Odontol Scand. 1974;32(1):61-70.

5. Bergenholtz G. Micro-Organisms from Necrotic Pulp of Traumatized Teeth. Odontol Revy. 1974;25(4):347-58.

6. Sundqvist, G. Bacteriologic studies of necrotic pulps Umea, Sweden: University of Umea; 1976.

7. Kakehashi S, Stanley HR, Fitzgerald RJ. The Effects of Surgical Exposures of Dental Pulps in Germ-Free and Conventional Laboratory Rats. Oral Surg Oral Med Oral Pathol. 1965 Sep;20:340-9.

8. Moller AJ, Fabricius L, Dahlen G, Ohman AE, Heyden G. Influence on Periapical Tissues of Indigenous Oral Bacteria and Necrotic Pulp Tissue in Monkeys. Scand J Dent Res. 1981 Dec;89(6):475-84.

9. Dalton BC, Orstavik D, Phillips C, Pettiette M, Trope M. Bacterial Reduction with NickelTitanium Rotary Instrumentation. J Endod. 1998 Nov;24(11):763-7.

10. Shuping GB, Orstavik D, Sigurdsson A, Trope M. Reduction of Intracanal Bacteria using Nickel-Titanium Rotary Instrumentation and various Medications. J Endod. 2000 Dec;26(12):751-5.

11. Card SJ, Sigurdsson A, Orstavik D, Trope M. The Effectiveness of Increased Apical Enlargement in Reducing Intracanal Bacteria. J Endod. 2002 Nov;28(11):779-83.

12. Bystrom A, Sundqvist G. Bacteriologic Evaluation of the Effect of 0.5 Percent Sodium Hypochlorite in Endodontic Therapy. Oral Surg Oral Med Oral Pathol. 1983 Mar;55(3):30712.

13. Sjogren U, Figdor D, Spangberg L, Sundqvist G. The Antimicrobial Effect of Calcium Hydroxide as a Short-Term Intracanal Dressing. Int Endod J. 1991 May;24(3):119-25. 
14. Sjogren U, Figdor D, Persson S, Sundqvist G. Influence of Infection at the Time of Root Filling on the Outcome of Endodontic Treatment of Teeth with Apical Periodontitis. Int Endod J. 1997 Sep;30(5):297-306.

15. Bystrom A, Happonen RP, Sjogren U, Sundqvist G. Healing of Periapical Lesions of Pulpless Teeth After Endodontic Treatment with Controlled Asepsis. Endod Dent Traumatol. 1987 Apr;3(2):58-63.

16. Katebzadeh N, Dalton BC, Trope M. Strengthening Immature Teeth during and After Apexification. J Endod. 1998 Apr;24(4):256-9.

17. Cvek M. Treatment of Non-Vital Permanent Incisors with Calcium Hydroxide. I. FollowUp of Periapical Repair and Apical Closure of Immature Roots. Odontol Revy. 1972;23(1):27-44.

18. Andreasen JO, Farik B, Munksgaard EC. Long-Term Calcium Hydroxide as a Root Canal Dressing may Increase Risk of Root Fracture. Dent Traumatol. 2002 Jun;18(3):134-7.

19. Sciaky I, Pisanti S. Localization of Calcium Placed Over Amputated Pulps in Dogs' Teeth. J Dent Res. 1960 Nov-Dec;39:1128-32.

20. Pisanti S, Sciaky I. Origin of Calcium in the Repair Wall After Pulp Exposure in the Dog. J Dent Res. 1964 Sep-Oct;43:641-4.

21. Cox CF, Keall CL, Keall HJ, Ostro E, Bergenholtz G. Biocompatibility of Surface-Sealed Dental Materials Against Exposed Pulps. J Prosthet Dent. 1987 Jan;57(1):1-8.

22. Kling M, Cvek M, Mejare I. Rate and Predictability of Pulp Revascularization in Therapeutically Reimplanted Permanent Incisors. Endod Dent Traumatol. 1986 Jun;2(3):839.

23. Yanpiset K, Trope M. Pulp Revascularization of Replanted Immature Dog Teeth After Different Treatment Methods. Endod Dent Traumatol. 2000 Oct;16(5):211-7.

24. Ebeleseder KA, Friehs S, Ruda C, Pertl C, Glockner K, Hulla H. A Study of Replanted Permanent Teeth in Different Age Groups. Endod Dent Traumatol. 1998 Dec;14(6):274-8.

25. Hitchcock R, Ellis E,3rd, Cox CF. Intentional Vital Root Transection: A 52-Week Histopathologic Study in Macaca Mulatta. Oral Surg Oral Med Oral Pathol. 1985 Jul;60(1):2-14.

26. Cvek M, Cleaton-Jones P, Austin J, Lownie J, Kling M, Fatti P. Effect of Topical Application of Doxycycline on Pulp Revascularization and Periodontal Healing in Reimplanted Monkey Incisors. Endod Dent Traumatol. 1990 Aug;6(4):170-6.

27. Cvek M, Cleaton-Jones P, Austin J, Lownie J, Kling M, Fatti P. Pulp Revascularization in Reimplanted Immature Monkey Incisors--Predictability and the Effect of Antibiotic Systemic Prophylaxis. Endod Dent Traumatol. 1990 Aug;6(4):157-69. 
28. Ritter AL, Ritter AV, Murrah V, Sigurdsson A, Trope M. Pulp Revascularization of Replanted Immature Dog Teeth After Treatment with Minocycline and Doxycycline Assessed by Laser Doppler Flowmetry, Radiography, and Histology. Dent Traumatol. 2004 Apr;20(2):75-84.

29. Nygaard-Ostby B, Hjortdal O. Tissue Formation in the Root Canal Following Pulp Removal. Scand J Dent Res. 1971;79(5):333-49.

30. Horsted P, Nygaard-Ostby B. Tissue Formation in the Root Canal After Total Pulpectomy and Partial Root Filling. Oral Surg Oral Med Oral Pathol. 1978 Aug;46(2):27582.

31. Davis MS, Joseph SW, Bucher JF. Periapical and Intracanal Healing Following Incomplete Root Canal Fillings in Dogs. Oral Surg Oral Med Oral Pathol. 1971 May;31(5):662-75.

32. Myers WC, Fountain SB. Dental Pulp Regeneration Aided by Blood and Blood Substitutes After Experimentally Induced Periapical Infection. Oral Surg Oral Med Oral Pathol. 1974 Mar;37(3):441-50.

33. Hoshino E, Kurihara-Ando N, Sato I, Uematsu H, Sato M, Kota K, Iwaku M. In-Vitro Antibacterial Susceptibility of Bacteria Taken from Infected Root Dentine to a Mixture of Ciprofloxacin, Metronidazole and Minocycline. Int Endod J. 1996 Mar;29(2):125-30.

34. Sato I, Ando-Kurihara N, Kota K, Iwaku M, Hoshino E. Sterilization of Infected RootCanal Dentine by Topical Application of a Mixture of Ciprofloxacin, Metronidazole and Minocycline in Situ. Int Endod J. 1996 Mar;29(2):118-24.

35. Takushige T, Cruz EV, Asgor Moral A, Hoshino E. Endodontic Treatment of Primary Teeth using a Combination of Antibacterial Drugs. Int Endod J. 2004 Feb;37(2):132-8.

36. Windley W,3rd, Teixeira F, Levin L, Sigurdsson A, Trope M. Disinfection of Immature Teeth with a Triple Antibiotic Paste. J Endod. 2005 Jun;31(6):439-43.

37. Torneck CD. Reaction of Rat Connective Tissue to Polyethylene Tube Implants. I. Oral Surg Oral Med Oral Pathol. 1966 Mar;21(3):379-87.

38. Torneck CD. Reaction of Rat Connective Tissue to Polyethylene Tube Implants. II. Oral Surg Oral Med Oral Pathol. 1967 Nov;24(5):674-83.

39. Nevins AJ, Finkelstein F, Borden BG, Laporta R. Revitalization of Pulpless Open Apex Teeth in Rhesus Monkeys, using Collagen-Calcium Phosphate Gel. J Endod. 1976 Jun;2(6):159-65.

40. Nevins A, Wrobel W, Valachovic R, Finkelstein F. Hard Tissue Induction into Pulpless Open-Apex Teeth using Collagen-Calcium Phosphate Gel. J Endod. 1977 Nov;3(11):431-3. 
41. Nevins A, Finkelstein F, Laporta R, Borden BG. Induction of Hard Tissue into Pulpless Open-Apex Teeth using Collagen-Calcium Phosphate Gel. J Endod. 1978 Mar;4(3):76-81.

42. Nevins AJ, LaPorta RF, Borden BG, Spangberg LS. Pulpotomy and Partial Pulpectomy Procedures in Monkey Teeth using Cross-Linked Collagen-Calcium Phosphate Gel. Oral Surg Oral Med Oral Pathol. 1980 Apr;49(4):360-5.

43. Nevins A, Crespi P. A Clinical Study using the Collagen Gel Zyplast in Endodontic Treatment. J Endod. 1998 Sep;24(9):610-3.

44. Schroder U, Granath LE. Early Reaction of Intact Human Teeth to Calcium Hydroxide Following Experimental Pulpotomy and its Significance to the Development of Hard Tissue Barrier. Odontol Revy. 1971;22(4):379-95.

45. Rule DC, Winter GB. Root Growth and Apical Repair Subsequent to Pulpal Necrosis in Children. Br Dent J. 1966 Jun 21;120(12):586-90.

46. Iwaya SI, Ikawa M, Kubota M. Revascularization of an Immature Permanent Tooth with Apical Periodontitis and Sinus Tract. Dent Traumatol. 2001 Aug;17(4):185-7.

47. Banchs F, Trope M. Revascularization of Immature Permanent Teeth with Apical Periodontitis: New Treatment Protocol? J Endod. 2004 Apr;30(4):196-200.

48. Harrison JW, Jurosky KA. Wound Healing in the Tissues of the Periodontium Following Periradicular Surgery. I. the Incisional Wound. J Endod. 1991 Sep;17(9):425-35.

49. Harrison JW, Jurosky KA. Wound Healing in the Tissues of the Periodontium Following Periradicular Surgery. 2. the Dissectional Wound. J Endod. 1991 Nov;17(11):544-52.

50. Maeda H, Wada N, Nakamuta H, Akamine A. Human Periapical Granulation Tissue Contains Osteogenic Cells. Cell Tissue Res. 2004 Feb;315(2):203-8.

51. Marx RE. Platelet-Rich Plasma: Evidence to Support its use. J Oral Maxillofac Surg. 2004 Apr;62(4):489-96.

52. Freymiller EG, Aghaloo TL. Platelet-Rich Plasma: Ready Or Not? J Oral Maxillofac Surg. 2004 Apr;62(4):484-8.

53. Strindberg LZ. The Dependence of the Results of Pulp Therapy on Certain Factors. an Analytic Study Based on Radiographic and Clinical Follow-Up Examinations. Acta Odontol Scand. 1956;14((Suppl. 14)). 